
Würzburger Vorträge zur Rechtsphilosophie, Rechtstheorie und Rechtssoziologie

Herausgegeben von Hasso Hofmann,

Edgar Michael Wenz und Dietmar Willoweit

Mitbegründet von Ulrich Weber

\section{Heft 17}




\section{Prof. Dr. Hasso Hofmann}

\section{Gebot, Vertrag, Sitte}

Die Urformen der Begründung von

Rechtsverbindlichkeit 
Vortrag gehalten am 22. Juli 1993

Die Deutsche Bibliothek - CIP-Einheitsaufnahme

\section{Hofmann, Hasso:}

Gebot, Vertrag, Sitte: Die Urformen der Begründung von Rechtsverbindlichkeit / Hasso Hofmann. - 1. Aufl. - Baden-Baden: Nomos Verl.-Ges., 1993

(Würzburger Vorträge zur Rechtsphilosophie, Rechtstheorie und Rechtssoziologie; H. 17) ISBN 3-7890-3194-1

NE: GT

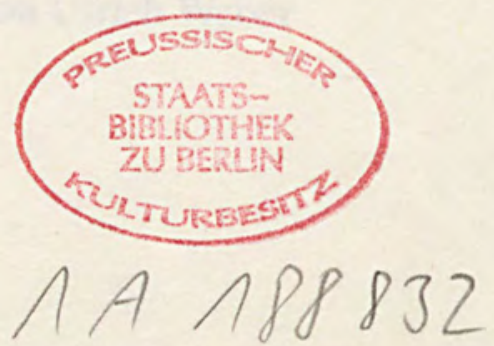

1. Auflage 1993

(c) Nomos Verlagsgesellschaft, Baden-Baden 1993. Printed in Germany. Alle Rechte, auch die des Nachdrucks von Auszügen, der photomechanischen Wieder-

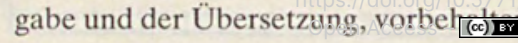




\section{geh. in. 1A 188832}

\section{Corrigenda}

\section{Hasso Hofmann}

Gebot, Vertrag, Sitte

Die Urformen der Begründung von Rechtsverbindlichkeit ISBN 3-7890-3194-1

(Würzburger Vorträge zur Rechtsphilosophie, Rechtstheorie und Rechtssoziologie, Bd. 17)

Bei der Abbildung 1 ist der Standort „Louvre (Paris)“, bei den Abbildungen 2 und 3 der Standort „Kunstsammlungen der Veste Coburg“" zu ergänzen. 


\section{Professor Alfred Voigt zum 80. Geburtstag}




\section{Editorial}

Gerade angesichts unserer reich blühenden Dogmatik des positiven Rechts und im Hinblick auf eine gewisse Tendenz, Rechtspraxis auf Rechtstechnik zu reduzieren, ist es wichtig, ja notwendig, über den kleinen Kreis derjenigen hinaus, die sich mit Rechtsphilosophie, Normentheorie oder Rechtssoziologie besonders befassen, Anstöße für die Beschäftigung mit den Grund- und Grenzfragen des Rechts zu geben. Wenigstens ab und an sollte auch der vorwiegend dogmatisch arbeitende Jurist - Student wie Praktiker - jene heilsame Unruhe verspüren, die aus der Begegnung mit den Frag-Würdigkeiten der Grundlagen und Methoden unseres Faches entspringt. Eine lockere Folge von Einzelvorträgen scheint uns hierfür aus mehreren Gründen das geeignete Mittel. So kann auf diese Weise am ehesten ein lebendiger Eindruck von Reichtum, Vielfalt und Spannweite der nichtdogmatischen Beschäftigung mit dem Recht entstehen. Reichen die Grund- und Grenzprobleme unseres Faches doch von der alten und unabweisbar immer neu sich stellenden Frage der Gerechtigkeit, der Frage des Rechts als Ausdruck menschlichen Selbstverständnisses über die moderne Normanalytik bis zur Bedeutung der sozialen Verhältnisse für Entstehung, Anwendung und Wirksamkeit der Gesetze wie für die Bildung von Rechtsbewußtsein.

Durch die Veröffentlichung dieser an der Universität Würzburg gehaltenen Vorträge möchten die Herausgeber darüber hinaus Texte zur Verfügung stellen, die über bestimmte Aspekte überschaubare Zugänge zur Theorie eröffnen, aber auch als Arbeitsmittel in Seminaren und Übungen dienen können.

Würzburg, im Juli 1984

Hasso Hofmann Ulrich Weber Edgar Michael Wenz 


\section{Gebot, Vertrag, Sitte}

Die Urformen der Begründung von Rechtsverbindlichkeit

I.

Die Frage nach der Verbindlichkeit des Rechts, die Frage also, ob dem Recht über seine äußere Zwangsgewalt hinaus eine innerlich verpflichtende Kraft zukomme, versteht sich nicht von selbst. Hat der aus der Trennung von Recht und Moral entspringende Rechtspositivismus ${ }^{1}$ doch längst $\mathrm{zu}$ der These geführt, daß das Recht - rein rechtlich betrachtet - zu nichts verpflichte ${ }^{2}$. Reduziert man die Rechtsordnung nämlich aus der Sicht des einzelnen auf äußeren Regelzwang und aus der Sicht des Staates auf Selbstregulierung der staatlichen Gewalt, dann sind die Motive des Rechtsgehorsams für den Rechtsbegriff in der Tat belanglos. Pflicht und Verpflichtung hören auf, juristische Kategorien zu sein ${ }^{3}$. Nachdem schon Kant die Innehabung eines Rechts als bloße Befugnis zur Zwangsanwendung definiert hatte ${ }^{4}$, scheint die Frage nach der inneren Verbindlichkeit des Rechts ausschließlich in den Be-

1 Dazu N. Hoerster, Verteidigung des Rechtspositivismus, 1989 (in dieser Reihe Heft 11), bes. S. 15 ff., wo S. 17 jedoch unklar bleibt, was wrechtliche Verbindlichkeit « des Rechts im Unterschied zur "moralischen Verbindlichkeit « des Rechts meint.

2 R. v. Jhering, Der Zweck im Recht, 1. Bd., 1877, S. 252; J. Binder, Rechtsnorm und Rechtspflicht, 1912, S. 47; R. Laun, Recht und Sittlichkeit, 3. Aufl. 1935, S. 8 .

3 Dazu H.-L. Schreiber, Der Begriff der Rechtspflicht, 1966; V. Kubes, Die Rechtspflicht, 1981; H. Hofmann, Grundpflichten als verfassungsrechtliche Dimension, in: VVDStRL 41 (1983), S. 42 (54 ff.).

4 Kant, Metaphysik der Sitten (Ed. Vorländer), S. 37. 
reich der Ethik oder der Psychologie zu gehören. Dieser Standpunkt ist die letzte Konsequenz aus einem Satz, der am nachreformatorischen Anfang der neueren europäischen Rechtslehre steht. Danach erweist sich die Qualität des wahren Gesetzes darin, daß es das Gewissen bindet: Non est vera lex, nisi quae obligat in conscientia. So steht es in dem neuscholastischen Riesenwerk des großen spanischen Jesuiten Franciscus Suarez De legibus ac deo legislatore von 1612 (Lib. III c.1). Damit wie mit seinen "Metaphysischen Disputationen " wirkte er aus hier im einzelnen nicht weiter zu verfolgenden Gründen über das katholische Europa hinaus für lange Zeit auch in die protestantischen Länder und deren Universitäten hinein ${ }^{5}$. Sein Grundsatz verbindet die alte Lehre von der Hierarchie der Normen und ihrer gestuften Verpflichtungskraft mit dem Angelpunkt der neuen Zeit: dem individuellen Gewissen. Wenn nun aber der göttliche Gesetzgeber, Gründer und Garant dieser Ordnung, in weltlichen Dingen keine zentrale Rolle mehr spielt ${ }^{6}$, dann kehrt sich das Verhältnis um. Wo das Gesetz nicht mehr kraft seiner jenseitig verbürgten inneren Wahrheit oder Vernünftigkeit das Gewissen bindet, da scheint nur noch die individuelle Gewissensentscheidung die äußerliche Zwangsregel zum verbindlichen Recht zu machen. Die statische objektive Hierarchie von Oben und Unten erliegt der dynamischen Antithese von subjektiver Innerlichkeit und bloß äußerlicher Gegebenheit ${ }^{7}$. "Dasjenige, was die Gewalt dekretiert hat und was an sich niemand verpflichtet«, sagte Rudolf Laun in seiner Hamburger Rektoratsrede von 1925 über »Recht und Sittlichkeit«, "wird für mich im einzelnen Anwendungsfall zum verbindli-

5 H. Dreitzel, Protestantischer Aristotelismus und absoluter Staat, 1970, S. 63 f.

6 Zu diesem Prozeß der "Entchristianisierung « W. Schmale, Entchristianisierung, Revolution und Verfassung, 1988, S. $20 \mathrm{ff}$.

7 Dazu H. Hofmann, Menschenrechtliche Autonomieansprüche, in: JZ 1992, S. 165 (167). 
chen Recht durch die Billigung meines Gewissens oder Rechtsgefühls $^{8}$.

Diese Leugnung einer die Kernbereiche des Rechts einschließenden objektiven Sittlichkeit entspricht indes nicht ganz den herrschenden sozialen Vorstellungen. Der Wiener Witz über ein neues Staatsschutzgesetz bringt es an den Tag: "§ 1 Wer auf einen Bundesminister schießt, wird mit 5 Jahren schweren Kerkers bestraft. $\S 2$ Wer auf den Bundeskanzler schießt, wird mit 10 Jahren schweren Kerkers bestraft. § 3 Auf den Bundespräsidenten darf überhaupt nicht geschossen werden."Wir empfinden es als überraschend und daher als witzig, wenn, wie das hier geschieht, eine nach dem Wenn-DannSchema indikativisch gefaßte Rechtsfolgeanordnung wörtlich genommen, ihr also kein Gebot oder Verbot, keine Handlungsnorm unterstellt und so der Anschein erweckt wird, diese Norm, nämlich das Verbot, müsse erst noch isoliert ausgesprochen werden. Anders herum: Es ist für uns nach wie vor überraschend, die Rechtsfolgeanordnung eines Strafgesetzes im nachhinein gewissermaßen nur als Preis für eine offene Handlungsmöglichkeit gedeutet zu sehen. Hart hat in seiner Analyse des Rechtsbegriffs wohl zutreffend festgestellt, daß die Menschen, wenn sie von einer rechtlichen Verpflichtung reden, etwas anderes als eine bloß moralische Verbindlichkeit oder Nötigung meinen, darunter aber auch nicht einfach die Drohung einer Sanktion verstehen'. Genauer gesagt: Rechtsnormen können als bloße Fakten mit kalkulierbaren Folgen betrachtet werden. Von dieser Möglichkeit der distanzierten, objektivierenden Sicht des quasi Außenstehenden macht jeder Gebrauch, der nichts anderes im Kopf hat als die Verfolgung seiner Interessen. In dieser Situation sind wir oft genug selbst -

8 Laun (N 2), S. 14.

9 H.L.A. Hart, The Concept of Law, Oxford 1961, dt.u.d.T. Der Begriff des Rechts, 1973. 
gegenüber dem Finanzamt beispielsweise oder im Straßenverkehr. Aber das ist weder die einzige noch die gewöhnliche Perspektive. Zumindest Normen von einer gewissen elementaren Bedeutung verstehen wir als verbindliche Verhaltenserwartungen einer legitimen Ordnung.

Wenn es demnach richtig ist, daß staatliche Anordnungen nicht nur dann als Recht gelten, wenn sie individuell als Recht anerkannt werden, dann können wir unser Problem auch in den Begriffen der Rechtsgeltung formulieren ${ }^{10}$. So gesehen handelt es sich um die Frage, worin die spezifisch normative Geltung des Rechts, d.h. der ihm gewöhnlich zugeschriebene, von den Adressaten zu erfüllende Anspruch der Maßgeblichkeit ${ }^{11}$ gründet. Genauer: worin wird das Fundament dieses Anspruchs gesehen? Dabei verschlägt es nichts, daß derartige Begründungsversuche möglicherweise, wie sogenannte Rechtsrealisten meinen, nur psychische Reflexe auf eine erzwungene Gewohnheit des Verhaltens sind ${ }^{12}$. Jener Grund aber kann logischerweise kein rechtlicher sein. Der normative Anspruch des Rechts ist nicht aus sich selbst heraus zu begründen. Das hat Kelsens Reine Rechtslehre ebenso demonstriert wie Luhmanns Rechtssoziologie. Denn: jede Rechtsordnung setzt die Unterscheidung von Richtigem und Unrichtigem, Recht und Unrecht. Daß aber überhaupt eine solche Grundunterscheidung, eine solche soziale "Codierung", sein solle, ist rein rechtlich nicht beweisbar. Folglich entstehen rings um die Idee der Normativität, der anspruchsvollen Maßgeblichkeit des Rechts und der daraus folgenden Bindungskraft, zwangsläufig

10 Dazu neuestens $R$. Alexy, Begriff und Geltung des Rechts, 1992, dessen Reduktionen indes von einem "voll ausgebildeten Begriff der rechtlichen Geltung (S. 142) wegführen.

11 Dazu H. Ryffel, Grundprobleme der Rechts- und Staatsphilosophie, 1969, S. 372 u. passim; jetzt v.a. J. Habermas, Faktizität und Geltung, 1992, S. 49 ff.

12 Siehe etwa $K$. Olivecrona, Gesetz und Staat, 1940, S. 12; dazu F. Fikentscher, Methoden des Rechts, Bd. II, 1975, S. 322 ff.; J. Bjarup, Skandinavischer Realismus: Hägerström - Lundstedt - Olivecrona - Ross, 1978. 
Vorstellungen, Bilder und Begriffe, die jene innere Bindung durch Recht über die Verknüpfung mit der Selbst- und Weltdeutung des Menschen plausibel zumachen bestimmt sind ${ }^{13}$. So schreibt der Rechtsphilosoph Karl Engisch - um hier vorab eine ganz geläufige Gedankenverbindung anzuführen - dem geltenden Recht um deswillen "verpflichtende Kraft« zu, weil "das Recht seiner Substanz nach aus Imperativen ... (bestehe) «, in denen sich ein Wille ausdrücke ${ }^{14}$. Ein anderer Kontext der Verbindlichkeitsfrage erschließt sich beispielsweise, wenn man Rechtsnormen nicht als Befehle, sondern als Wertungen oder Standards betrachtet ${ }^{15}$.

II.

Die hier zur Diskussion gestellte These ist, daß die weit über diese ersten Hinweise hinausgehenden vielfältigen Konnotationen der Idee rechtlicher Verpflichtungskraft um drei Grundfiguren, Schlüsselbegriffe, Kontextualisierungs- oder Verknüpfungselemente kreisen - wie immer man die Funktion dieser "Urphänomene« begrifflich charakterisieren mag. Ich nenne diese "Basisphänomene«: Gebot, Vertrag und Sitte. "Gebot" schließt hier selbstverständlich das Verbot und die hoheitliche Gewährung ein und akzentuiert zugleich das Moment der Entscheidung. "Vertrag " meint jede Art konsensuellen Verhaltens, ist also nicht in einem strengen juristischen Sinn zu nehmen. "Sitte" schließlich steht als Sammelbezeichnung für überlieferte Verhaltensmuster wie Brauch, Herkommen und Gewohnheiten, aber auch für objektive sittliche Ordnungen, die einer

13 H.J. Berman, Law and Revolution, 1983, dt. u. d.T. Recht und Revolution 1991, S. 37: "Das Recht (leitet) - in allen Gesellschaften - seine Autorität von etwas auBerhalb seiner selbst her. $\alpha$

14 K. Engisch, Einführung in das juristische Denken, 8. Aufl. 1983/89, S. 22.

15 Dazu B. Rüthers, Rechtsordnung und Wertordnung, 1986, S. 19 ff. 
Weltvernunft oder der Natur zugeschrieben, mithin in derselben Weise als vorgegeben gedacht werden.

Beiläufige Andeutungen dieser Dreiheit der Begriffe finden sich öfter. Für die Idee des Staates, heißt es in Hegels Rechtsphilosophie ( $§ 258$ ), sei dessen historischer Ursprung ebenso gleichgültig wie die Frage, ob die grundlegende Rechtsvorstellung "im Bewußtsein" als "göttliches, positives Recht", mithin als Anordnung, oder als »Vertrag, Gewohnheit und so fort gefaßt « sei. Die Pointe der hier vertretenen These liegt demgegenüber jedoch in der Behauptung einer exklusiven Trinität der Grundfiguren, wie es solche dreigliedrige Theorien nun einmal an sich haben, weil sie im Gegensatz zu allen spannungsvollen antithetischen Begriffsbildungen eine ausgeglichene geistige Ganzheit suggerieren. "Aller guten Dinge sind drei«, sagt der Volksmund in vielen Sprachen. Von der antiken Staatsformenüber die aufklärerische Gewaltenteilungslehre bis zu Hegels dialektischem Dreischritt wären da aus der Theoriegeschichte mancherlei Beispiele anzuführen. Drei Arten gebe es, Gesetze zu begreifen, schrieb Proudhon, gleichfalls nebenher und doch nicht zufällig gerade in seinem Werk über das föderative Prinzip: als Glaubender könne man das Gesetz für den Befehl einer höheren Autorität nehmen, als Philosoph darin - wie Montesquieu - den Ausdruck der Verhältnisse sehen, als Bürger aber das Gesetz im Sinne einer vereinbarten richterlichen Satzung des menschlichen Willens begreifen ${ }^{16}$.

Die Behauptung ist also, daß alle Konnotationen der Verbindlichkeit von Recht in einer spezifischen Weise einer jener drei Grundfiguren, Idealtypen oder Kristallisationsbegriffe Gebot, Vertrag, Sitte - zugeordnet und diese vielleicht miteinander verknüpft, nicht aber aufeinander zurückgeführt werden

16 P. -J. Proudhon, Du Principe Fédératif, Paris 1868 , S. 53 N. 1. Dazu A. Ritter, The Political Thought of Pierre-Joseph Proudhon, Princeton/NJ 1969, S. 155 ff.; K.S. Vincent, Pierre-Joseph Proudhon and the Rise of French Republican Socialism, New York/Oxford 1984, S. 209 ff. 
können. Daß es dabei, wie bei allen Idealtypen, Mischformen und Übergänge gibt, versteht sich von selbst. J

Auch dürfte es einleuchten, daß jede detailliert ausgearbeitete, durchgebildete Rechtstheorie stets mehrere Motive miteinander verbindet. Außerdem ist in komplexen Rechtsphilosophien, wie derjenigen Hegels etwa, natürlich auch mit Theoriestufen und -entwicklungen zu rechnen ${ }^{17}$. Andererseits tritt in gewissen historischen Konstellationen, vor dem Hintergrund bestimmter Erfahrungen, die eine oder andere Grundfigur geschichtsmächtig in den Vordergrund, indem sie sich gegen die anderen polemisch absetzt.

Die hier vertretene These hat natürlich Berührungspunkte mit Max Webers ternärer Idealtypik legitimer Herrschaft kraft Charismas einer Person, kraft Tradition und kraft Legalität einschließlich allerdings seiner Lehre von der nichtlegitimen Herrschaft, die im Zusammenhang mit dem Typus der Legitimität kraft Legalität gesehen werden muß. Darauf näher einzugehen, würde hier freilich zu weit führen ${ }^{18}$. Auch eine partielle Überschneidung mit Carl Schmitts These von den drei Arten rechtswissenschaftlichen Denkens in Entscheidungen, Normen oder konkreten Ordnungen muß hier auf sich beruhen. Ertragreicher als die Behandlung dieser politisch etwas opportu-

17 Vgl. etwa A. Honneth, Kampf um Anerkennung, 1992, zu Hegels Rechtsphilosophie.

18 Siehe dazu vom Verf., Die Legitimität der Legalität und deren Verwaltung, in: Zeitschr. f. Rechtssoziologie 13 (1992), S. 294 ff. Weber selbst hat die wehrhaften stadtbürgerlichen Schwurbruderschaften mit ihrer Herrschaft aus dem Willen der Beherrschten jedenfalls nicht unter die autoritären Herrschaftsformen gerechnet und wahrscheinlich deswegen seiner Typen-Trias nicht subsumiert, den naheliegenden vierten Legitimationsgedanken demokratischer Herrschaft aus noch weiter zu klärenden Gründen also bewußt ausgeblendet: $W$. Schluchter, Religion und Lebensführung, Bd. 2, 1988, S. 473; F.-J. Ehrle, Max Weber und Wien, phil. Diss. Freiburg/Br. 1991, S. 89 (92 f.). Instruktiv zu den Interpretationsproblemen im einzelnen $K$. Schreiner, Die mittelalterliche Stadt in Webers Analyse und die Deutung des okzidentalen Rationalismus, in: Max Weber, der Historiker, hg. v. J. Kocka, 1986, S. 119 (125 ff.). 
nistischen Schrift aus dem Jahre $1934^{19}$ scheint ein Blick auf Wilhelm Ebels vielzitierte Gesetzgebungsgeschichte ${ }^{20}$. Der Autor hat darin eine Trias von "Grundformen" der »deutschen Gesetzgebung " behauptet: "das ungesetzte Recht in Gestalt des Weistums - dann die von den Rechtsgenossen vereinbarte Satzung - und schließlich das vom Herrscher oder der sonstigen Obrigkeit befohlene Recht, das Rechtsgebot«. Indessen läßt sich der Reichtum der historischen Rechtsbildungsprozesse schwerlich auf diese angeblich exklusiven »begrifflichen Bauelemente der deutschen Gesetzgebungsgeschichte« reduzieren. Verlangen da doch auch Privilegien, Einungen, Rechtsbücher, gelehrte Schriften, Dekrete und Rezeptionen Berücksichtigung. Und wo jene drei Grundformen dingfest gemacht werden können, bleibt namentlich beim Weistum der kaum zu behebende Zweifel, ob die Weisung Kundiger über das in der jeweiligen Situation Herkömmliche und Rechte wirklich als ein Element begriffen werden kann, das "zur staatlichen Rechtsetzung unserer Tage führt", wie Ebel meinte. Zudem ergeben die Erläuterungen seiner Ausgangsthese, daß für Weistum auch Rechtsgewissen, für Satzung ebenso Konsens und für Rechtsgebot schließlich Befehl gesetzt werden könnte. Verdeutlicht man Ebels "reines Rechtsgewissen" noch mit "Bewußtsein vorgegebenen Rechts «, dann zeigt sich ein auf die bunte Fülle des geschichtlichen Materials angewandtes kategoriales Schema: Befehl - Vertrag - Herkommen. Diese Trias scheint indes weniger bestimmte geschichtliche Stufen der Rechtsetzung zu bezeichnen, als vielmehr in einer erhellenden Weise Schlüsselbegriffe zu benennen, die der Begründung rechtlicher Verbind-

19 C. Schmitt, Die drei Arten des rechtswissenschaftlichen Denkens, 1934; dazu $H$. Hofmann, Legitimität gegen Legalität, 2. Aufl. 1993, S. 177; ders., Schmitt, in: Staatslexikon der Görres-Gesellschaft, 7. Aufl., 4. Bd., 1988, Sp. 1052 (1054) mit weit. Nachw.

20 W. Ebel, Geschichte der Gesetzgebung in Deutschland, 2. Aufl. 1958, Neudr. 1988; die folg. Zit. ebd. S. 11, 8 u. 9. 
lichkeitsansprüche dienen - mit einem nach den historischen Umständen wechselnden Gewicht.

In diesem vorläufigen Vergleich ist schließlich noch auf Ernst Cassirers "Philosophie der Symbolischen Formen " hinzuweisen. Der Nachlaß enthält Vorarbeiten zu einem vierten Band. Sie scheinen durch die Auseinandersetzung mit Heidegger veranlaßt zu sein und enthalten im Zusammenhang einer "Metaphysik der menschlichen Erfahrung" eine Theorie der "Basisphänomene ${ }^{21}$. Nach Cassirer liegt die Grundstruktur des Gewahrens der phänomenalen Wirklichkeit in der Trias von "Selbst", »Wirken « und »Werk«. Und diese spiegele sich in der Dreiheit der Personalpronomina Ich, Du und Es. Mit dem Rekurs auf diese grammatische Grundstruktur ist der Punkt erreicht, von dem aus die hier vorgetragenen Überlegungen im Anschluß an eine Studie vergleichender Religionswissenschaft von Wolfgang Philipp ${ }^{22}$ vor vielen Jahren ihren Anfang genommen haben. ${ }^{23}$ Unter dem Einfluß von Nietzsches These, daß wir allemal im "Bann bestimmter grammatischer Funktionen " denken, suchen sie den strukturellen Zusammenhang aufzudecken, der zwischen verschiedenen Auffassungen von der Verpflichtungskraft des Rechts einerseits und gewissen Prinzipien des Selbst- und Weltverständnisses andererseits besteht, Grundsätzen, die entweder das Dasein der einigenden Existenz einer befehlenden Über-Ich-Autorität oder das unpersönliche So-Sein der Welt und bestimmter Traditionen oder das dialogische Miteinander-Sein von Ich und $\mathrm{Du}$ in der zukunftsmächtigen politischen Aktion des Wir zum Inhalt haben.

21 Dies u. das Folg. nach $O$. Schwemmer, Der Werkbegriff in der Metaphysik der symbolischen Formen, in: Internat. Zeitschr. f. Philosophie, 1992, S. 226 ff.

22 Die Absolutheit des Christentums und die Summe der Anthropologie, 1959.

$23 \mathrm{Vgl}$. Hofmann, Legitimität gegen Legalität (N 19), S. 181 N 22, - Ein erster Entwurf der Theorie ist im akad. Jahr 1989/90 im Wissenschaftskolleg zu Berlin entstanden und dort diskutiert sowie bei der Siemens-Stiftung in München vorgetragen worden; eine spätere Fassung war Grundlage eines Vortrags in der Philosoph. Fakultät der Universität Tübingen. 
Schlüsselt man die Theoriegeschichte von daher auf, ergeben sich Gruppen von Konnotationen, also Gedankenverbindungen oder Begleitvorstellungen, die in der nachfolgenden Übersicht aufgelistet sind. In den Kolumnen unter den Grundfiguren "Gebot", "Vertrag " und "Sitte" erscheinen die jeweils im Zusammenhang damit hervortretenden Gedanken oder Begriffe. Diese Begleitvorstellungen sind ihrerseits nach den seitlich angeführten Kategorien von "Person", "Tugend ", "Sein", "Raum«, "Zeit« usw. geordnet.

Konnotationen der Verbindlichkeit des Rechts

\begin{tabular}{|c|c|c|c|}
\hline & Gebot & Vertrag & Sitte \\
\hline Person & $\begin{array}{l}\text { Vater } \\
\text { Autorität } \\
\text { eines Höheren } \\
\text { oder Selbst- } \\
\text { bestimmung }\end{array}$ & $\begin{array}{l}\text { Selbsterfah- } \\
\text { rung im } \\
\text { anderen }\end{array}$ & $\begin{array}{l}\text { Mutter, das } \\
\text { Mütterliche, } \\
\text { Leben, Natur, } \\
\text { Geschichte = } \\
\text { Transpersonale } \\
\text { Macht, obj. } \\
\text { Geschehen }\end{array}$ \\
\hline Tugend & $\begin{array}{l}\text { Gehorsam, } \\
\text { Selbstdiszi- } \\
\text { plin }\end{array}$ & $\begin{array}{l}\text { Offenheit, } \\
\text { Treue, Bür- } \\
\text { gertugend }\end{array}$ & $\begin{array}{l}\text { Hingabe, } \\
\text { Ergeben- } \\
\text { heit }\end{array}$ \\
\hline Sein & Dasein & $\begin{array}{l}\text { Miteinander- } \\
\text { sein }\end{array}$ & Sosein \\
\hline Raum & $\begin{array}{l}\text { Über-/Unter- } \\
\text { ordnung }\end{array}$ & $\begin{array}{l}\text { Nebeneinander, } \\
\text { Gleich- } \\
\text { ordnung }\end{array}$ & $\begin{array}{l}\text { Aufruhen, } \\
\text { getragen wer- } \\
\text { den, einge- } \\
\text { schlossen } \\
\text { sein, } \\
\text { Teil-Ganzes }\end{array}$ \\
\hline
\end{tabular}




$\begin{array}{llll}\text { Zeit } & \begin{array}{l}\text { Stetige } \\ \text { Gegenwart }\end{array} & \text { Zukunft } & \begin{array}{l}\text { Uranfänglich- } \\ \text { keit, Konstanz } \\ \text { im Wandel, } \\ \text { Zeitlosigkeit, } \\ \text { Vergangenheit, } \\ \text { Produktivität } \\ \text { der Geschichte }\end{array} \\ \text { Aktion } & \begin{array}{l}\text { Befehlen, } \\ \text { entschei- } \\ \text { den, } \\ \text { zwingen }\end{array} & \begin{array}{l}\text { Miteinander } \\ \text { sprechen u. } \\ \text { handeln, } \\ \text { sich } \\ \text { vertragen, } \\ \text { versprechen, } \\ \text { übereinstimmen }\end{array} & \begin{array}{l}\text { Erkennen, Ein- } \\ \text { sicht in Not- } \\ \text { wendigkeiten, } \\ \text { naturgemäß } \\ \text { leben, bewahren }\end{array} \\ & & \end{array}$

\begin{tabular}{llll} 
Recht & Richter- & Gleichheit, & Herkommen, \\
könig, & Freiheit, & Gewohnheit, \\
Einzelfall- & kollektive & Sittlichkeit, \\
gerechtig- & Selbst- & Mythos, \\
keit, Schutz & herrschaft, & Wachstum, \\
u. Gehorsam & Satzung, & Organismus, \\
& Organisation & Volk, Natur \\
& von Ordnung & der Sache, \\
& & Geborgenheit \\
\hline
\end{tabular}

$\begin{array}{llll}\text { Gramma- } & \text { Ich/gedachtes } & \text { Du-Wir } & \text { Es } \\ \text { tika- } & \text { Über-Ich } & & \end{array}$

lische

Grund-

figur

Für die schon erwähnte Theorie, wonach das Recht Verpflichtungskraft habe, weil es aus Imperativen bestehe, ergibt sich aus dieser Übersicht beispielsweise: Diese Vorstellung begreift Ordnung prinzipiell als Über-/Unterordnung, setzt die Autorität einer höheren Instanz voraus, korrespondiert mit patriarchalischen Anschauungen, unterstellt in ganz unhistorischer Weise die beständige Gegenwart des gesetzgeberischen Willens und erwartet Gehorsam. Fühlen wir uns durch das 
Recht dagegen verpflichtet, weil es letztlich diskursiv ermittelt ist und wir uns versprochen haben, dann korrespondieren dem offenkundig andere Seinserfahrungen, andere räumliche Ordnungsvorstellungen und insbesondere eine andere Zeitperspektive, wonach das Heil in der Zukunft liegt. Zudem dominieren andere Aktionsformen und andere rechtliche Grundwerte. Ontologische Naturrechtslehren schließlich, aber auch geschichtlich bestimmte Rechtstheorien erweisen sich als eingebettet in ein Beziehungsgeflecht unpersönlicher, es-hafter Konnotationen.

Bei alledem sei noch einmal betont: Es handelt sich hier nicht um eine Theorie des Rechts und der Begründung seiner Verpflichtungskraft, sondern um eine Theorie über die Struktur entsprechender Auffassungen, Lehren und Theorien. Eine Theorie über Theorien, eine Metatheorie also - das scheint eine ziemlich abstrakte Angelegenheit. Deshalb seien den exemplarischen Einzelanalysen einige Illustrationen vorgeschaltet.

\section{III.}

Die erste Abbildung zeigt ein berühmtes Staatsporträt Ludwigs XIV. von Rigaud aus dem Jahre $1701^{24}$. Der König erscheint als Personifikation des Staates: er verkörpert ihn und stellt ihn zugleich dar. Sein Wille ist Gesetz aus dem einzigen Grund, weil es ihm so gefällt: Car tel est nostre plaisir, steht auf seinen Gesetzesurkunden. Nach Jean Bodins berühmten "Sechs Büchern über die Republik" von 1576 hatte sich im 17. Jahrhundert die Auffassung durchgesetzt, daß im Gegensatz zum früheren Richterkönigtum hauptsächlich die imperativische Gesetzgebung Zeichen der höchsten, nun als Souveränität

24 Dazu K. Ahrens, Hyacinthe Rigauds Staatsportrăt Ludwigs XIV., 1990. Zum folg. auch $H$. Mohnhaupt, Potestas legislatoria und Gesetzesbegriff im Ancien Régime, in: Ius Commune IV (1972), S. 188 (199 ff.). 
begriffenen Gewalt sei. Fortan macht der souveräne Wille des Herrschers die wahre Substanz des Gesetzes aus. Immer wieder wird die Digestenstelle 1, 4, 1 (Ulpian) zitiert: Quod principi placuit, legis habet vigorem. Die bindende Kraft des Gesetzes rührt danach allein von dem Befehl eines divinen Menschen her. Unter dem hochgerafften Vorhang, der eine Enthüllung ansagt und als Thronbaldachin, das Himmelsgewölbe symbolisierend, den geheiligten Erscheinungsort des Herrschers bezeichnet, hat dieser sich um eine Stufe zum Betrachter herabgelassen. Sein wiederum himmelsgleicher Krönungsmantel will als priesterliches Gewand verstanden werden. Dessen Raffung offenbart nicht nur die ritterliche Unterbekleidung und das Krönungsschwert, welches den rechten Glauben verteidigt, sondern auch den "Tanzmeisterschritt" des Monarchen. Diese den höchsten Würdenträgern vorbehaltene zeremonielle Stellung verweist auf den höfischen Tanz, der Ordnung und Harmonie des Staates in Analogie zur harmonia mundi darstellt.

Zur zweiten Abbildung: Der Stich gibt die Eröffnung der Generalstände am 5. Mai 1789 in Versailles wieder ${ }^{25}$. Mit der Einberufung der Etats Généraux versuchte Ludwig XVI. zur Abwendung des Staatsbankrotts eine Einrichtung wiederzubeleben, die Ludwig XIV. durch die Konzentration des Staates in seiner Person überwunden hatte. Man sieht die Vertreter der drei Stände, nämlich der Geistlichkeit (links), des Adels (rechts) und (im Vordergrund) des sog. Dritten Standes der Nichtprivilegierten, in Blöcken ausgerichtet auf den thronenden König, oder genauer: auf das Königtum, auf die das Bild beherrschende Krone, während hinter der Säulenreihe die Hofgesellschaft zuschaut. Besonders wichtig ist hier die zeremoniell-repräsentative, prunkvolle Unpersönlichkeit der Darstellung und die starke, in die Vergangenheit des Reiches zurück-

25 Hierzu u. zum folg. F. Gross, Volk und Massen - Beweger der Geschichte, in Bildern seit 1789-1989: Zweihundert Jahre Französische Revolution, Ausstellungskatalog d. Staatl. Kunsthalle Berlin, 1989, S. 87 ff. 
Abb. 1

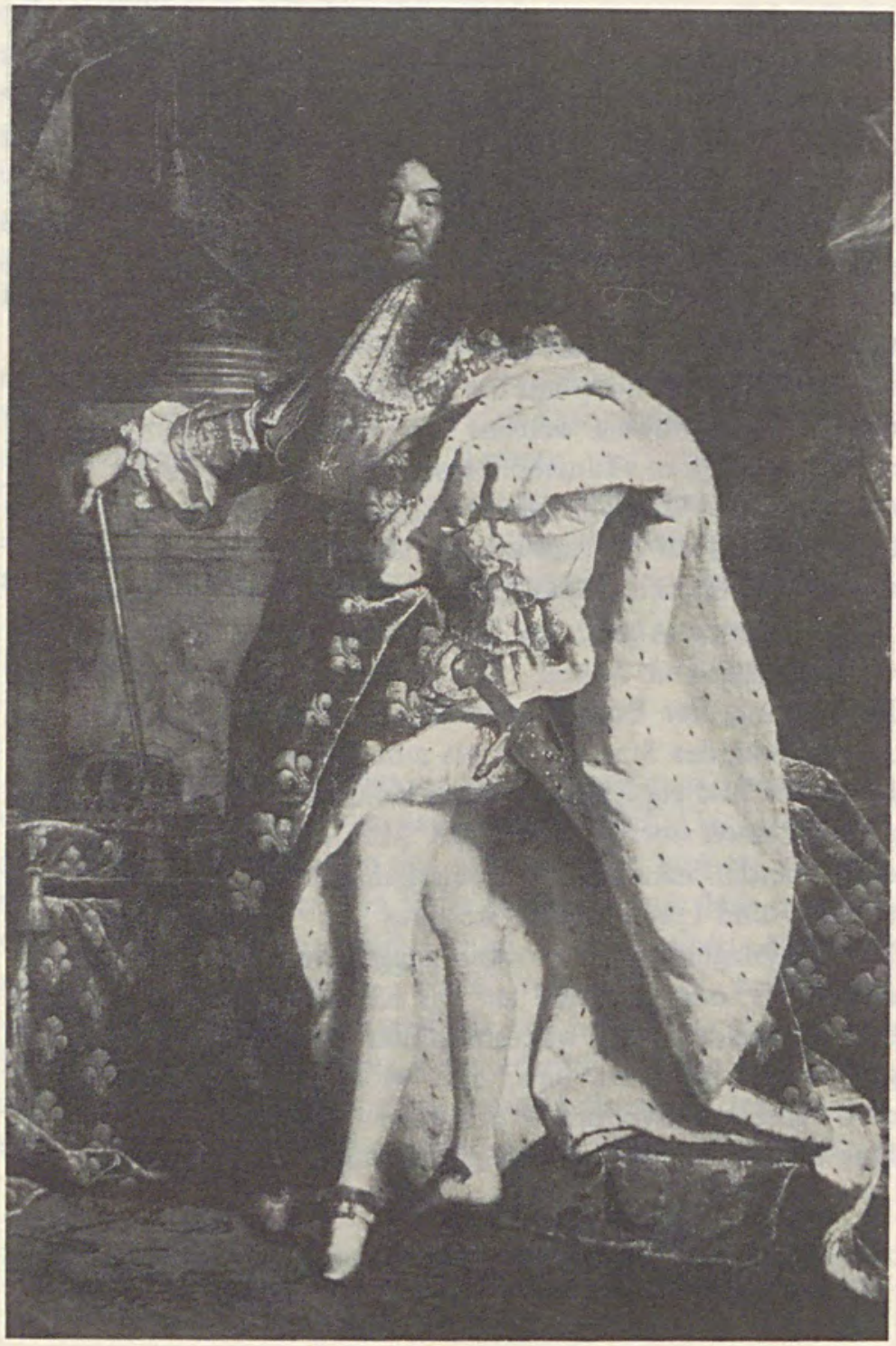


Abb. 2

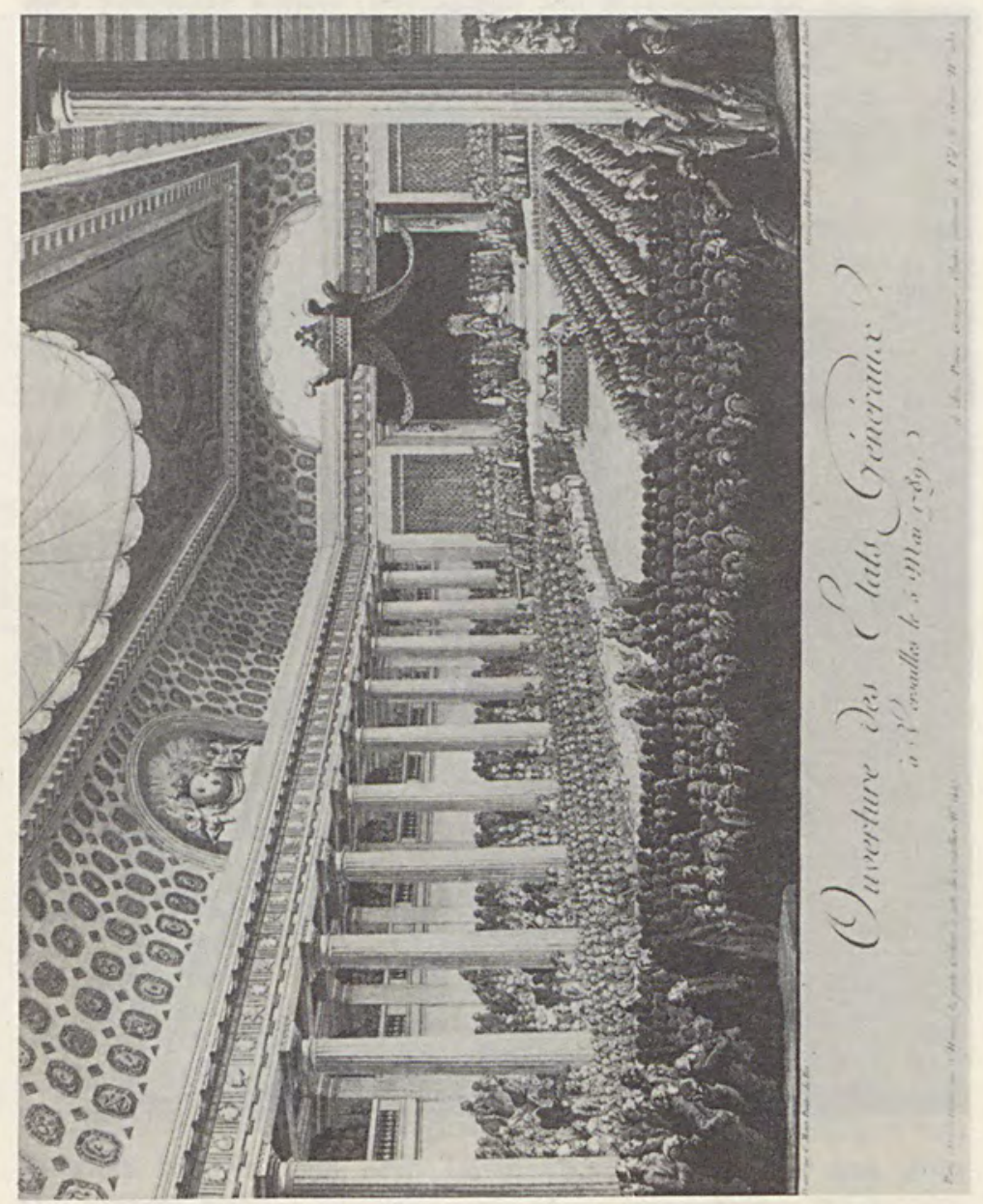


Abb. 3

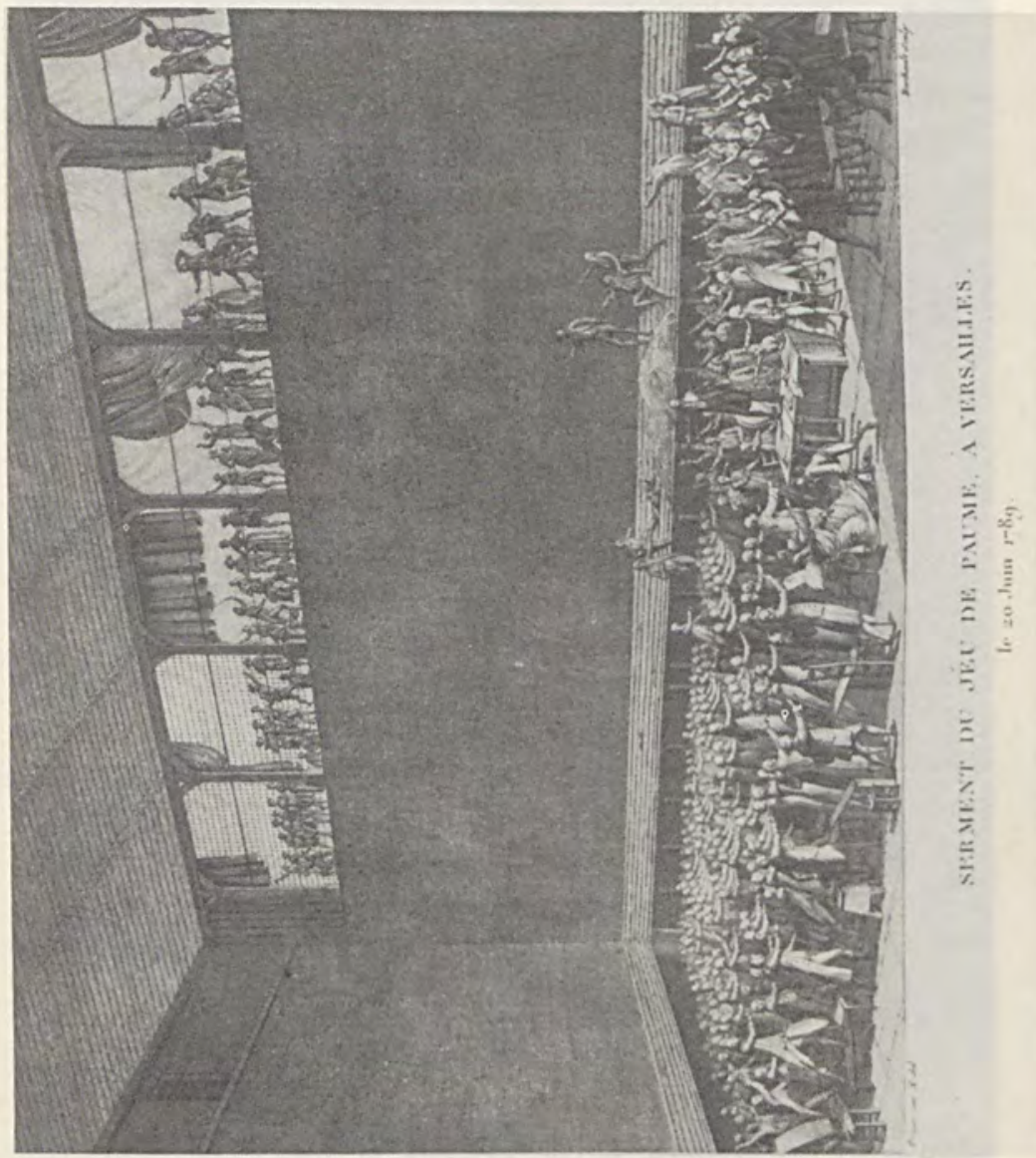

weisende Betonung des Institutionellen. Die Darstellung suggeriert, daß das, was hier beschlossen wird, deswegen verpflichtet, weil es auf der altüberlieferten, hierarchisch alle einschließenden Ordnung des Reiches beruht. 
Im äußersten Gegensatz dazu steht die Szene des Ballhausschwures vom 20. Juni 1789 und deren Darstellung durch den Zeichner Prieur, der selbst ein Revolutionär der ersten Stunde war (Abbildung 3). Statt steifem Zeremoniell und höfischem Prunk: kahle Wände, tabula rasa, Neuanfang; Improvisation einer bürgerlichen Ratsstube in dem nach der Überlieferung tatsächlich völlig leeren Saal; zukunftsgerichteter Enthusiasmus; Gleichheit, die den auf dem Tisch stehenden, nur seiner Funktion wegen sich heraushebenden Präsidenten der Nationalversammlung (den Astronomen Bailly) einschließt; sind einige doch noch höher geklettert als er, um besser zu hören - alles keine Rangunterschiede; stattdessen: brüderliche Umarmungen; Solidarität in der gleichartigen Bewegung der Schwurarme.

Nachdem sich der Dritte Stand drei Tage zuvor im Wege des Staatsstreichs zur Nationalversammlung erklärt hatte, war sein Versammlungsraum versperrt worden. So wich man in das leere Ballhaus aus und schwor sich, nicht auseinanderzugehen, bis man eine Verfassung geschaffen, d.h. dem Reich eine neue Rechtsgrundlage gegeben habe. Das Ganze erscheint als bürgerliche conjuratio oder "Einung ", mit der - wie ehedem in den freien Städten des Mittelalters - der Grund für ein neues Staatswesen gelegt wird ${ }^{26}$. Hier sind unschwer alle Konnotationen der Vertrags-Kolumne unserer Übersicht zu assoziieren.

IV.

Die vierte Abbildung zeigt das Titelkupfer des Leviathan von Thomas Hobbes aus dem Jahre 1651. Indem wir uns dem Hauptvertreter der Theorie zuwenden, wonach das Recht aus

26 Dazu die Nachw. bei H. Hofmann, Die versprochene Menschenwürde, Druck der Humboldt-Universität zu Berlin 1993, S. 34 N 100. Siehe ferner St. Breuer, Die blockierte Rationalisierung, in: Arch. f. Kulturgesch. 66 (1984), S. 47 ff. 
Abb. 4

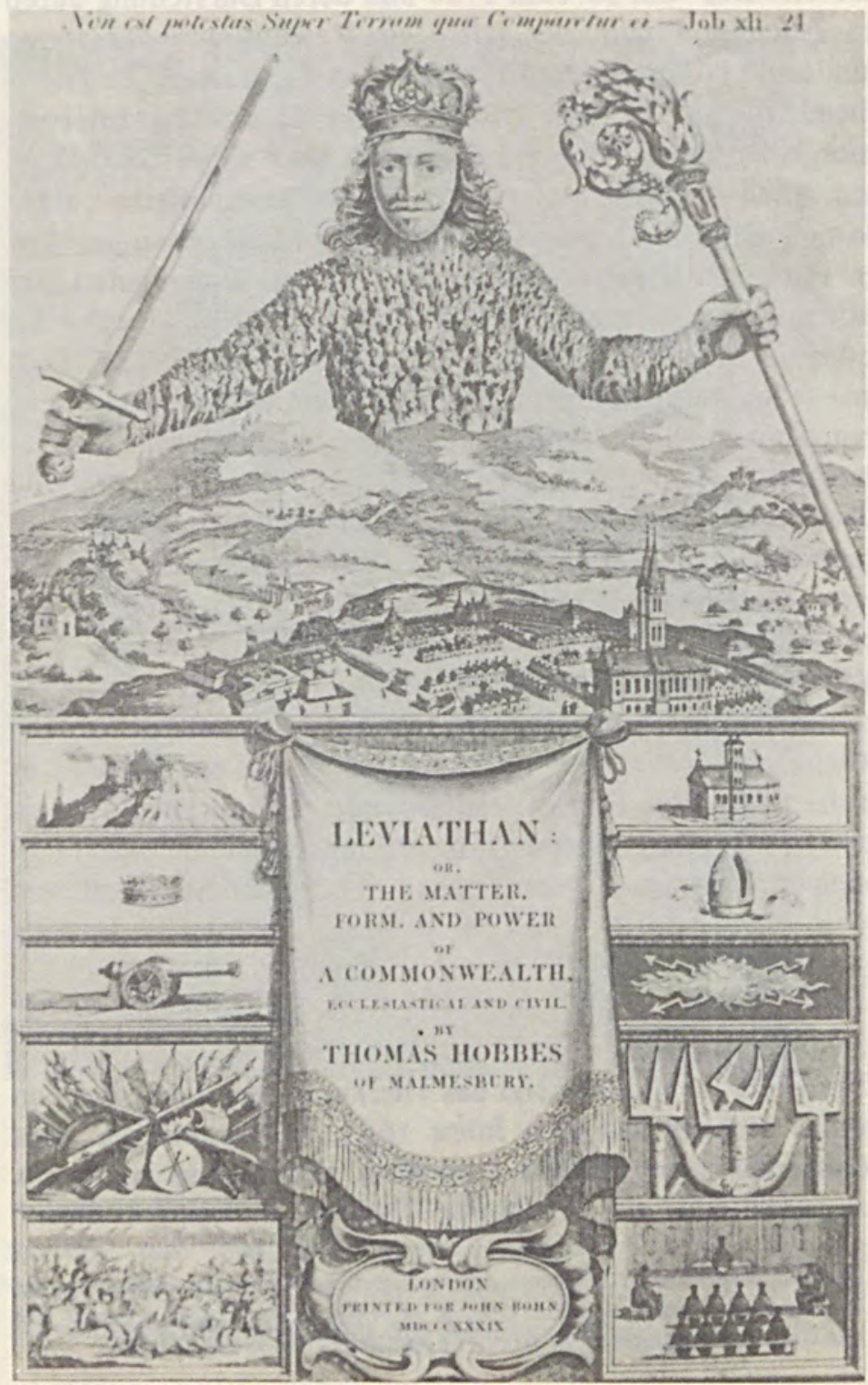


Imperativen besteht und seine Verbindlichkeit aus dem Willen eines Imperators bezieht, gehen wir zu den analytischen Teilen unserer Betrachtung über.

Wiewohl 50 Jahre älter als Rigauds Darstellung Ludwigs XIV. greift das Bild des Leviathan staatstheoretisch vor. Hobbes hat das Titelblatt wahrscheinlich selbst entworfen ${ }^{27}$. Auf dem Platz links vor der Kirche gehen einzelne Menschen ihren privaten Tätigkeiten nach; Rechtspersonen sind sie jedoch nur dadurch, daß sie ihre Person im corpus des Fürsten aufgeben. Nur der Fürst selbst scheint als natürliches und rechtliches Wesen mit sich selbst identisch. Sein etwas rundliches Gesicht mit den herabwallenden Locken dort, wo die Sonne über der Landschaft stehen könnte, scheint das Motiv des Sonnenkönigs anklingen zu lassen. Dagegen spricht allerdings, daß der Körper nicht in der Mittelachse steht, womit statt des Hauptes das Herz in den Mittelpunkt rückt: vielleicht eine Folge der Entdeckung des Blutkreislaufs im Jahre 1628 durch William Harvey, mit dem Hobbes persönlichen Kontakt hatte. Der Fürst beschirmt das Land als weltlicher und geistlicher Herrscher. Die Symbole der weltlichen und geistlichen Gewalt, Schwert und Bischofsstab, werden durch die Bildleisten auf der unteren Hälfte in genauer Parallele weitergeführt. Es gibt keine Gewalt auf Erden, die diesem Herrscher vergleichbar wäre - so wie das Buch Hiob $(41,24)$ eben dies von dem Seeungeheuer Leviathan sagt: Non est potestas super terram quae comparetur $e i$. Daher der Name Leviathan für den Staat. Wegen seiner Machtfülle ist es nach Hobbes' Worten der Name eines "sterblichen Gottes «, dessen aus Menschenleibern zusammengesetzter Körper dem corpus Christi mysticum ${ }^{28}$ gleicht. Nach mittelalterlicher Vorstellung hat der christliche Herrscher Teil an der Herrschaft Christi. Demgemäß drückt das Bildnis des

27 Hierzu u. zum folg. die ungemein eindringliche Analyse von $R$. Brandt, Das Titelblatt des Leviathan, in: Leviathan 1987, S. $163 \mathrm{ff}$.

28 Dazu H. Hofmann, Repräsentation, 2. Aufl. 1990, S. 121 ff. 
Königs die Überzeugung von der unmittelbaren Gegenwart Christi aus ${ }^{29}$. Die geweihte monarchische Herrschaft reicht auf diese Weise buchstäblich in den Himmel und repräsentiert die ewige göttliche Herrschaft, den in ewiger Gegenwart anwesenden Willen Gottes ${ }^{30}$. Auch Hobbes' Fürst ist offenkundig über allem und überall, aber sichtbar schon deswegen, weil er den politischen Willen aller einzelnen absorbiert hat. Die Statik des Bildes vermittelt reine Gegenwart, die sich in der Zeitund Geschichtslosigkeit der nachfolgenden Theorie wiederholt. Das Dasein des Fürsten, der die Einheit der Bürger ist (und nicht nur bedeutet) ${ }^{31}$, verbürgt Frieden. Das Bild macht klar, daß dieser Frieden entgegen der aristotelischen Tradition nichts Natürliches, sondern eine ungeheuer künstliche Veranstaltung ist.

Recht in seinem Wesen als Befehl zu begreifen, bedeutet aber nicht nur, die Verpflichtungskraft des Rechts mit dessen Ordnungsleistung zu begründen. Das wäre trivial. Vielmehr umschließt die Denkfigur des Rechtsgebots als Kontextualisierungsbegriff darüber hinaus die Vorstellung vom staatlichen Gesetzgeber als einer existierenden überindividuellen und selbst ganz und gar subjektiven, ich-haften Wissens- und Willenseinheit. Auf sie weisen die Gesetze als Imperative zurück. Der Staat als Person, als ein Über-Ich, das Befehle gibt - dieser Gedanke führt die alte Metapher vom Gemeinwesen als einem Makroanthropos $^{32}$ fort. Das gedachte Ich des Gesetzgebers ist wie der vom wirklichen Verfasser zu unterscheidende fiktive

29 H. Keller, Herrscherbild und Herrscherlegitimation, in: Frühmittelalterliche Studien, hg. v. K. Hanck, Bd. 19, 1985, S. 290 ff.

30 Dazu O. Treitinger, Die oströmische Kaiser- und Rechtsidee nach ihrer Gestaltung im höfischen Zeremoniell, Nachdr. 1956, 3. Aufl., 1969, S. 122 f. u. passim.

31 Dazu G. Duso, Der Begriff der Repräsentation bei Hegel und das moderne Problem der politischen Einheit, 1990, S. 7 ff. (in dieser Reihe Heft 12).

32 Siehe v.a. Johann von Salisbury, Polycraticus IV 1-3 (zit. nach Joannis Saresberiensis Opera omnia, ed. J.A. Giles, Vol. III, Oxford 1848, Fotomech. Nachdr. Leipzig 1969); dazu Hofmann, Repräsentation (N 28), S. 97 f., 121 ff., 281 f. 
Ich- oder Er-Erzähler einer Geschichte ${ }^{33}$ in allen Rezeptionsvorgängen präsent, gleichwohl für niemanden ein geschwisterliches Du und über jede Art von solidarischem Du-Wir-Gefühl erhaben.

Diese scharfe Betonung der Ich-Struktur und der Bezug auf das eigene Selbst im Denken über Gemeinschaft, Herrschaft und Recht ist neu und revolutionär ${ }^{34}$, neu und revolutionär die Punktualität der Vorstellung von Recht, das als Befehl allein im Willen des Sprechenden gründet: in voluntate dicentis, wie die lat. Fassung des Leviathan sagt (Cap. XXV). Wir kennen die Schwierigkeiten, welche die Landesherren hatten, als sie seit dem 15. Jahrhundert zunehmend versuchten, neben den herkömmlichen Rechtsvorstellungen und gegen das Rechtsgewissen der Schöffen ihre landesherrlichen Gebote als Recht zu etablieren $^{35}$. Authoritas, non veritas, facit legem, heißt es bei Hobbes im 26. Kapitel in Übereinstimmung mit dem, was schon Jean Bodin gelehrt und Montaigne in seinen Essays (Von der Erfahrung) von 1580 so ausgedrückt hatte: "... die Gesetze (behalten) ihr Ansehen nicht deshalb, weil sie gerecht sind, sondern nur dadurch, daß sie Gesetze sind. Das ist der geheimnisvolle Grund ihrer Autorität; es gibt keinen anderen." Das Gesetz beansprucht danach nicht deswegen Geltung, weil es aus der Wahrheit kommt und folglich richtig und gerecht ist, sondern weil der Souverän es kraft seiner Autorität gesetzt hat. Es verlangt daher auch keinen Glauben an seine Richtigkeit, sondern nur Befolgung. In diesem Sinne ist das staatliche Gesetz ein Befehl. Die Autorität des Souveräns sieht Hobbes aus einem Vertrag hervorgehen, der in Wahrheit aber keiner ist, sondern eher eine Summe einseitiger Ermächtigungs- oder Un-

33 Über die für die Rezeption geringe Bedeutung dieses Unterschieds: $H .-W$. Ludwig/W. Faulstich, Erzählperspektive empirisch, 1985, S. 144 ff.

34 Dazu D. Henrich, Ethik zum nuklearen Frieden, 1990, S. 285, 289 f., 307 ff.

35 Dazu D. Willoweit, Deutsche Verfassungsgeschichte, 2. Aufl. 1992, § 14 III u. IV 2. $\S 18$. 
terwerfungsakte. Vor der Gründung der Einheit durch Unterwerfung unter einen Souverän gibt es nämlich keine individuelle oder kollektive rechtlich-politische Subjektivität, weil es im Naturzustand überhaupt keinerlei rechtlich-politische Gemeinsamkeit gibt. Und im bürgerlichen Zustand ist die rechtliche und politische Subjektivität im Souverän konzentriert. Durch Übertragung der "gesamten Macht und Stärke " aller "auf einen Menschen oder eine Versammlung von Menschen, die ihre Einzelwillen durch Stimmenmehrheit auf einen Willen reduzieren können", entsteht nach Hobbes eine wirkliche Einheit aller in ein und derselben Person: a real unity of them all, in one and the same person, wie die engl. Fassung des Leviathan sagt (Chap. 17). Da alle sich ihr, der Souveränitätsperson, unterworfen haben, sind sie alle auch Autoren der Akte des Souveräns. Außer ihm gibt es folglich weder ein individuelles noch ein kollektives Subjekt politischen Handelns, sondern nur die atomistische Menge der Untertanen. Der Souverän nimmt deren Rechtssubjektivität in sich auf: he bears their person (Chap. 17). Es gibt in dieser Konstruktion kein "Du " und kein "Wir". Allerdings kann das große Ich den kleinen Ichs das nicht verbindlich befehlen, was sie selbst nicht wirksam zu versprechen vermögen, nämlich das eigene Leben zu gefährden oder gar es hinzugeben. Das läßt der Selbsterhaltungstrieb nicht zu und widerspräche dem Zweck der Unterwerfung ${ }^{36}$. Hier wird der Abstand von einer politischen Ordnung besonders deutlich, die - auf einem Treueversprechen aller beruhend - den tugendhaften Bürger Sokrates sogar auf ein Fehlurteil hin freiwillig in den Tod gehen läßt.

Im rechtlichen Ergebnis entsprechen die Hobbes'schen Formeln vom souveränen Gesetzgeber jenen, mit denen das Papsttum gegen den Konziliarismus theoretisch restauriert worden

36 Daraus folgt jedoch kein Widerstandsrecht im eigentlichen Sinn: H. Hofmann, Bemerkungen zur Hobbes-Interpretation, in: ders., Recht-Politik-Verfassung, 1986. S. 58 ( $67 \mathrm{ff}$.). 
war $^{37}$. Daß der Papst die Kirche genannt werden könne, so wie Hobbes den König mit dem Volk gleichsetzt (De Cive XII $\S 98$ ), hatte allerdings Aegidius von Rom schon um 1302 geschrieben. Die Theorie des fürstlichen Absolutismus mit dessen Gebotsrecht, von der wir im Zusammenhang mit dem Staatsporträt Ludwigs XIV. bereits gesprochen haben, weist letztlich also auf die sog. päpstliche Revolution zurück, in der die Papstkirche seit dem 11. Jh. durch bewußte Rechtsetzung und Rechtsgestaltung anstaltliche Eigenständigkeit gewonnen hatte $^{38}$. Der revolutionäre Einsatz des Rechts als einer Sozialtechnik stiftet eine neue Ordnung und erschließt damit zugleich für den subjektiven hierarchischen Gestaltungswillen einen neuen Raum des Machbaren. Gewissermaßen das Manifest dieser Revolution ist der Dictatus Papae Gregors VII. von 1075. Drückt sich der absolute Leitungsanspruch dieses ungemein willensstarken Papstes doch vornehmlich in der unerhörten Behauptung aus, daß er und er allein befugt sei, nach Bedarf neue Gesetze zu geben ${ }^{39}$.

Das Erbe des großen, souveränen Ich des politischen Makroanthropos hat später das sich ins Allgemeine übersteigende Ich der idealistischen Philosophie angetreten, welches sich nach Fichte in einem tätigen Akt selbst setzt und die Welt nur noch als seine Begrenzung begreift ${ }^{40}$. Unter dem kategorischen Imperativ Kants erhebt sich das Bewußtsein des einzelnen Menschen ins Allgemeine und macht sich als sittlich autonomes Subjekt die Befolgung der gegebenen Rechtsnormen selbst zur Pflicht ${ }^{41}$. Damit wird der einzelne als Vernunftwesen selbst

37 Hierzu und zum folg. Hofmann, Repräsentation (N 28), S. 281 ff., 313 ff.

38 Dazu Berman (N 13), passim; siehe auch Mohnhaupt (N 24), S. 203 f. Zum zentralen Punkt der Veränderung des Verständnisses der Papstwahl P. Schmid, Der Begriff der kanonischen Wahl in den Anfängen des Investiturstreits, 1926, S. 94 ff.

39 Text des Dictatus bei K. Kroeschell, Deutsche Rechtsgeschichte 1, 1972, S. 174 f.

40 J.G. Fichte, Grundlage des Naturrechts nach Prinzipien der Wissenschaftslehre, 1796 (Ed. M. Zahn 1960).

41 Kant, Metaphysik der Sitten (N 4), S. 21 ff., 35. 
und unmittelbar zum Imperator der rechtlichen Imperative, zum moralischen Urheber der inneren Verbindlichkeit des positiven (von Kant empirisch genannten) Rechts.

Auch Kants Subjekt der Sittlichkeit ist als homo noumenon wie der Hobbes'sche Leviathan ein gedachtes, kein empirisches Ich. Die für den einzelnen geltenden Gebote werden vom Vernunft-Ich allerdings nicht willkürlich gesetzt, sondern in einer als Erkenntnisvorgang verstandenen Selbstreflexion hervorgebracht. Die von ihnen verursachte innere Nötigung ist gleichwohl die von Sollens-Geboten. Umgekehrt folgt der Untertan nach Hobbes' Konstruktion ebenfalls sich selbst, wenn er den Befehlen des Souveräns gehorcht - was ihm die Vernunft der Selbsterhaltung gebietet. Die Unterschiede sind mithin inhaltlicher, nicht struktureller Art. Eine juristische Lehre, nämlich die sogenannte individuelle Anerkennungstheorie, wonach erst die Anerkennung des einzelnen dem Rechtssatz zur Verbindlichkeit verhilft, hat zuerst der wackere Altliberale Welcker daraus geformt ${ }^{42}$.

Freiwillige Befolgung statt Befehl und Zwang: mit der Überzeugungskraft des monarchischen Staatsmodells schwindet auch die der Imperativentheorie ${ }^{43}$. Wenn wir Rechtssätze in gewissem Umfang gleichwohl auch heute noch als Befehlssätze

42 C. Th. Welcker, Die letzten Gründe von Recht, Staat und Strafe, 1813, S. 71 ff. Zu den dann bei E.R. Bierling zutagetretenden Schwierigkeiten dieser Theorie Hofmann, Legitimität und Rechtsgeltung, 1977, S. 45 f. Siehe auch eingangs bei N 2 , 7 u. 8. Eine letzte Konsequenz dieses im Grunde anarchistischen Ansatzes findet sich in Kelsens Reiner Rechtslehre: H. Dreier, Rechtslehre, Staatssoziologie und Demokratietheorie bei Hans Kelsen, 2. Aufl. 1990, S. 125 N 211.

43 Diesen Zusammenhang belegt v.a. Bierlings Werk; siehe dazu N 42. Charakteristisch auch $A$. Thon, Rechtsnorm und subjectives Recht, 1878, S. 8: "Das gesamte Recht einer Gemeinschaft ist nichts als ein Complex von Imperativen ... * Die wideale Macht « dieser Imperative liege win der ganzen Wucht des allgemeinen Willens, der sich in der Norm an den Willen des ihr Unterworfenen wendet «(S. 6 f.). Die Befugnis besonderer legislativer Organe zur Gesetzgebung sei letztlich aber immer gewohnheitsrechtlich begründet (S. $1 \mathrm{f}$. N 4). Die heute maßgebliche Behandlung der Imperativentheorie findet sich bei Hart (N 9). 
bezeichnen, so hat das nur eine rechtstechnische oder funktionale, keine legitimatorische Bedeutung mehr.

\section{V.}

Gegen die Lehre des Hobbes, daß das Recht Gesetz und das Gesetz Befehl einer Autorität sei, steht ein anderer Satz. Er hat das Denken der Menschen über die Jahrhunderte nicht weniger stark geprägt. Epikur, einer der letzten großen Weisheitslehrer Athens, hat ihn von den Sophisten, den griechischen Aufklärern ${ }^{44}$, übernommen und epigrammatisch formuliert: "Das Recht ist eine Vereinbarung" ( $\sigma \dot{\omega} \mu \beta 0 \lambda \circ v)$ - ein "Vertrag " ( $\sigma u v \theta \dot{x} x \eta)$ nämlich »über das Nützliche zum Zwecke der Verhütung gegenseitiger Schädigung. ${ }^{45}$ Diese Lehre ist eine Konsequenz der griechischen Abwendung von der "Vorstellung, daß im Grunde nur eine (gedanklich) vorgegebene Ordnung recht sein konnte ${ }^{46}$. Die damit gewonnene Verfügung über die Rechtsordnung ist zugleich Frucht einer Entwicklung, in der breitere Schichten der Polis sich und die anderen, welche soziale Rolle sie sonst auch spielen mochten, als Bürger begreifen, die an den Entscheidungen für das Ganze teilhaben. Man hat das die "Entstehung des Politischen bei den Griechen " genannt. Es handelt sich dabei um die Erfahrung spezifisch bürgerlicher Kommunikation, die Entdeckung des Ich und des Du und folglich des Wir in den alle betreffenden Angelegenheiten. Verträge setzen ein Gegenüber und Miteinander, eine Kommunikation von Rechtssubjekten voraus. Daran fehlt es in der Konstruktion des sog. "Herrschaftsvertrages " bei Hobbes. Sein Souverän hat innerhalb des Staates kein Gegen-

44 Dazu E. Wolf, Griechisches Rechtsdenken II, 1952.

45 Epikur, Kyriai doxai 31-33; zit. nach A. Voigt (Hg.), Der Herrschaftsvertrag, 1965, S. 45.

46 Ch. Meier, Die Entstehung des Politischen bei den Griechen, 1980, S. 154. 
über. Und außerhalb des Staates gibt es keine Rechtsgemeinschaft. Von allen dazu autorisiert schafft Hobbes' Souverän, dieses hochpotenzierte Ich, das Recht ganz allein.

Die Geschichte der Vorstellung, daß menschliche Gemeinschaft, Recht und Staat aus einem Vertrag hervorgehen, ist reich an Facetten ${ }^{47}$. Auch dieser Gedanke hat ja nicht nur die Theorie beschäftigt, sondern - von den mittelalterlichen Herrschaftsverträgen bis zum Pakt der Pilgerväter auf der Mayflower - in vielen Gestaltungen die Praxis der Rechtserzeugung bestimmt ${ }^{48}$. Daraus ist ihm umgekehrt wiederum ideelle Überzeugungskraft zugewachsen, ebenso wie der Imperativenlehre aus der Staatspraxis des Absolutismus.

Hier interessiert indes nur die Struktur der Vorstellung vertraglicher Begründung einer Rechtsgemeinschaft. Ihr wirkungsmächtiger Propagandist der Neuzeit war neben John Locke bekanntlich Jean-Jacques Rousseau. Die Schlüsselworte seiner Definition des Gesellschaftsvertrages sind: "Jeder von uns " und: "Wir als Körperschaft": "Jeder von uns " - so lautet seine bekannte Formulierung des Gesellschaftsvertrages "stellt gemeinsam mit den anderen seine Person und seine ganze Kraft unter die höchste Leitung des Gemeinwillens; und wir als Körperschaft nehmen jedes Mitglied als vom Ganzen unabtrennbaren Teil auf" (Contrat social I, 6). Wird die Rechtsetzung nun als zentrale Aktion des so gebildeten Staatskörpers begriffen, und zwar als eine diesem Prinzip strukturell entsprechende Aktion, so ist nach Rousseau klar, "daß das, was ein Mensch - wer immer es auch sein möge - nach seinem eigenen Kopf befiehlt, kein Gesetz ist « (Cs II 6). Unmöglich also, daß das Gesetz im Willen dessen gründet, der den Geset-

47 Dazu aus der neueren Lit. W. Kersting, Vertrag, Gesellschaftsvertrag, Herrschaftsvertrag, in: Geschichtliche Grundbegriffe, hg. v. O. Brunner u.a., Bd. 6, 1990, S. $901 \mathrm{ff}$.

48 Dazu H. Hofmann, Zur Idee des Staatsgrundgesetzes, in: ders., Recht-Politik-Verfassung, 1986, S. 261 (269). 
zesbefehl ausspricht, wie Hobbes gesagt hatte. Gesetz kann danach vielmehr nur das sein, was Rousseau die volonté générale nennt und als gemeinsamen Willen definiert ( Cs II, 2, 3 u. 6).

Eine solche Art rechtlicher Willensbildung beruht - hier nicht anders als einst bei den Sophisten und bei Epikur - auf der Voraussetzung gleicher Freiheit aller. Doch gründet das staatliche Recht nach Rousseau nicht unmittelbar in dieser Basisannahme, sondern erst in der dadurch inspirierten gemeinsamen revolutionären Tat einer paktierten Grundordnung. Eine strukturgerechte Entwicklung des Vertragsgedankens muß aber über die bloße Konstituierung einer Autorität hinausgehen und die fortdauernde Wahrung der wirklichen Gemeinsamkeit des politischen Willens bedenken. Denn diese ist allemal durch Selbstsucht bedroht. Wer in dem die politische Struktur bestimmenden Sinne Rousseaus über einen Gesellschaftsvertrag redet, kann daher nicht umhin, auch vom wahren Bürger und seiner Tugend zu sprechen ${ }^{49}$. Darin liegt der eine Grund dafür, daß Vertrags- und Konsenstheorien des Rechts zwangsläufig eine viel innigere Verbindung mit der Ethik haben als alle Imperativentheorien, denen die Moral nur als heterogene Schranke der Herrschaft erscheint. Der andere Grund ist der, daß der Gedanke eines Urvertrages die wechselseitige Anerkennung aller als Person impliziert. Denn nur so, nämlich moralisch, kann die Verbindlichkeit einer Übereinkunft begründet werden, welche die Rechtsgemeinschaft ja allererst stiften soll.

Schließlich ist den Rechtsbegründungsauffassungen der DuWir-Grammatik eine prinzipiell andere Art der Repräsentation des Gemeinwesens zuzuordnen als allen Theorien vom staatlichen Über-Ich. Hier stehen die in der mittelalterlichen Korporationenlehre entwickelten Formen der Caput-Repräsentation und der Corpus-Repräsentation gegeneinander ${ }^{50}$. Im einen

49 Hierzu H. Münkler, Politische Tugend, in: Chancen der Freiheit, hg. v. dems., 1992 , S. $25 \mathrm{ff}$.

50 Hierzu und zum folg. H. Hofmann, Der spätmittelalterliche Rechtsbegriff der Repräsentation in Reich und Kirche, in: Der Staat 27 (1988), S. 523 ff. 
Fall handelt es sich um die Darstellung politischer Einheit, deren Haupt oder Spitze sie personifiziert, im anderen um die Herstellung, die Bildung der Einheit durch das Verhalten ihrer Mitglieder. Ist das eine zeremonielles Rollenspiel eines einzelnen, so das andere autonom organisierte kollektive Handlung. Ein besonders schönes Beispiel dieser republikanischen Corpus-Repräsentation bietet die Allegorie des Buon Governo von Ambrogio Lorenzetti im Palazzo Pubblico von Siena ${ }^{51}$. Aber auch den Fries vom Festzug der Athener beim großen Athenafest an der Cellawand des Parthenon könnte man hier nennen, weil er den in der Kulthandlung geeinten Demos zeigt ${ }^{52}$. Wichtig ist dabei allemal, zwischen dem Wir-Gefühl eines heterokephal durch eine Autorität oder bloß auf unpersönliche Weise durch eine sachliche Gemeinsamkeit zusammengehaltenen Kollektivs einerseits ${ }^{53}$ und einem Wir-Bewußtsein zu unterscheiden, das aus der wechselseitigen Anerkennung von Individualitäten resultiert ${ }^{54}$.

Rousseaus Demokratiemodell ist offenkundig utopisch: Traum von der freien Solidarität in der systemisch differenzierten Gesellschaft ${ }^{55}$. Die Menschen werden ja nicht wie Insektenschwärme generationsweise neu geboren, können also die

51 Dazu vorzüglich Qu. Skinner, Ambrogio Lorenzetti: The Artist as Political Philosopher, in: Proceedings of the British Academy, Vol. LXXII 1986, Oxford 1987, S. 1 ff., auch in: Malerei und Stadtkultur in der Dantezeit, hg. v. H. Belting u. D. Blume, 1989, S. 85 ff. Instruktiv ferner W. Schild, Gerechtigkeitsbilder, in: Recht und Gerechtigkeit im Spiegel der europäischen Kunst, hg. v. W. Pleister u. dems., 1988, S. 86 (130 ff.); zum Problem auch Th. Fröschl, Selbstdarstellung und Staatssymbolik in den europäischen Republiken der frühen Neuzeit usw., in: Republiken und Republikanismus im Europa der Frühen Neuzeit, hg. v. H.G. Koenigsberger, 1988, S. $239 \mathrm{ff}$.

52 Siehe F. Brommer, Die Parthenon-Skulpturen, 1979, S. 48 ff.; J. Boardman, The Parthenon and its Sculptures, London 1985, S. 26 ff.

53 W. Kaufmann nennt ein solches Wir-Gefühl, wie es v.a. bei sog. "Bewegungen « zu beobachten ist, kindlich und regressiv: Without Guilt and Justice, New York 1973, dt. u. d.T. Jenseits von Schuld und Gerechtigkeit, 1974, S. 18.

54 Dazu Hofmann, Menschenwürde (N 26), S. 15 f.

55 G. Kirsch, Das freie Individuum und der dividierte Mensch, 1990, S. 182. 
Form ihrer politischen Existenz nicht von Generation zu Generation völlig frei vereinbaren. Ein Dilemma der statisch-konsensualen wie der prozedural-diskurstheoretischen Begründung der Geltung einer Rechtsordnung besteht mithin darin, das Postulat von Diskurs und Konsens gegen die Verselbständigung der notwendigen Institutionalisierungen durchzuhalten, ohne die institutionellen Sicherungen von Entscheidungsfähigkeit zu negieren. Von der weiteren Schwierigkeit eines erhöhten Bedarfs an stabilisierender moralischer Gemeinwohlorientierung war schon die Rede. Rousseau hat deshalb eine staatsbürgerliche Religion gefordert ( $C s$ IV 8 ). Dieser notwendige Zusammenhang hält sich in der gegenwärtigen Prozeduralisierung der Konsenstheorie durch. Auch die diskurstheoretische Begründung der Rechtsgeltung bedarf gewisser Idealisierungen. Sie stehen als Postulate z.B. der Wahrhaftigkeit, der Autonomie des einzelnen und der Bereitschaft, Bindungen einzugehen, am Anfang des Einigungsprozesses. Da ferner am Ende die "schwache Kraft rationaler Motivation" durch die Vernunft kommunikativen Handelns nicht ausreicht, wie Habermas sagt, "die Umsetzung der Einsichten in motiviertes Handeln ... sicher(zu)stellen ${ }^{56}$, ist dann erst recht demokratischer Bürgersinn vonnöten.

Derselbe Zug moralischer Strenge und republikanischer Tugendhaftigkeit tritt auch in W. Henkes originellem Versuch hervor, die Verbindlichkeit des Rechts aus zwischenmenschlichen Handlungen zu begründen, statt sie in einer personalen Autorität zu verankern oder aus irgendwelchen übergreifenden Sphären herzuleiten. Die strukturelle Eindeutigkeit dieses Entwurfs verdankt sich der Anlehnung an F. Gogartens unorthodox-lutherische Theologie des "Zwischen" und an M. Bubers dialogisches Prinzip ${ }^{57}$.

56 Habermas (N 11), S. 19; siehe dazu ebd. S. $51 \mathrm{f}$., $121 \mathrm{ff} ., 641 \mathrm{f}$.

57 W. Henke, Recht und Staat, 1988. Dazu H. Hofmann, Gerechtigkeit der privaten und öffentlichen Rechtsverhältnisse durch juristische Amtstätigkeit, in: Der Staat 30 (1991), S. 245 ff. 
Ein ganz besonderes Problem der konsensualen oder - prozedural gedacht - diskurstheoretischen Geltungsbegründung liegt schließlich in dem Universalismus der politischen Grammatik des Du-Ich-Wir mit ihren Grundwerten der allgemeinen Gleichheit und Freiheit. Wenn Rousseau in seiner Formel des Gesellschaftsvertrages "Wir" sagt und "Jeder von uns", dann fehlt der eingrenzende Bezug auf eine bestimmte existierende politische Gemeinschaft unter den vielen anderen. Gewiß: Rousseau dachte dabei an die heimatliche Stadtrepublik Genf oder kleine Schweizer Kantone, und der Inhalt der Theorie setzt in der Tat kleinräumige Verhältnisse voraus. Aber das ändert nichts daran, daß das "Wir" seines "Gesellschaftsvertrages " theoretisch wir alle sind und daß der Text gerade daraus seine Überzeugungskraft zieht. Diese Spannung zwischen der Abstraktheit und Universalität des Prinzips der Rechtsbegründung aus dem Konsens autonomer Individuen auf der einen Seite und den konkreten Bedingungen der politisch, historisch, kulturell und sozial so vielgestaltigen Welt andererseits kehrt auch in der einflußreichen Erneuerung der aufklärerischen Vertragstheorie durch John Rawls wieder. Zeigt sich dessen "Theorie der Gerechtigkeit" (1971) doch unentschieden zwischen der abstrakten philosophischen Begründung einer universalen Gerechtigkeitstheorie für die moderne Welt mit Hilfe der alten vernunftrechtlichen Theoreme von Naturzustand und Gesellschafts- bzw. Herrschaftsvertrag einerseits und der politischen Selbstverständigung der nordamerikanischen Gesellschaft über die normativen Grundlagen ihres historisch-konkreten Zusammenlebens andererseits. Habermas hat das kritisiert ${ }^{58}$. Seine diskurstheoretische Rechtsphilosophie (»Faktizität und Geltung ", 1992), welche die alte Konsenstheorie in eine Philosophie des Verfahrens und der kraft Verfahrens notwendig möglichen Zustimmung aller Betroffenen transformiert, ist dabei in der Perspektive des Du-Wir tat-

58 Habermas (N 11), S. $78 \mathrm{ff}$. 
sächlich von größerer struktureller Konsequenz. Der fragliche Widerspruch erscheint bei ihm im Gegensatz zwischen dem Modell der spontan assoziierten Rechtsgemeinschaft freier und gleicher Rechtsgenossen und dem (sie sozusagen trübenden) politisch-kulturellen Kontext einer vorpolitischen, ethnischkulturellen Gemeinschaft, ferner in der Differenz zwischen dem universellen Diskurs über moralische zwischenmenschliche Probleme einerseits und dem partikularen Diskurs über politisch-ethische Fragen des kollektiven Selbstverständnisses andererseits wie schließlich in der Unterscheidung von moralischer und politischer Autonomie. Indessen behauptet bei Habermas der moralische und damit der universelle Diskurs den logischen Primat. Für das Selbstbestimmungsrecht eines Volkes folgt daraus, daß es zwar das Recht hat, die eigene, durch die Idee des Rechtsstaates der Freien und Gleichen, also nach universellen Prinzipien definierte politische Existenz zu bewahren, nicht aber die überlieferte kulturelle Lebensform gegenüber andrängenden anderen kulturellen Lebensarten privilegieren darf ${ }^{59}$. Ontologisch gewendet: Das Miteinandersein des Du-Ich-Wir fügt sich als freies Zueinanderfinden weder der Kategorie des individuellen Daseins noch der des transpersonalen Soseins ${ }^{60}$.

\section{VI.}

Hier tritt der traditionsbewußte, das transpersonale Sein und Geschehen betonende Konservativismus auf den Plan ${ }^{61}$. Der große englische Revolutionskritiker Edmund Burke folgt der

59 Ebd. S. 659.

60 Dazu allgemein $K$. Löwith, Das Individuum in der Rolle des Mitmenschen, in: ders., Sämtl. Schriften, Bd. 1, 1981, S. 9 ff.; speziell zu einer Ontologie der Relationen A. Kaufmann, Beiträge zur Juristischen Hermeneutik, 1984, S. 89 ( 96 ff.).

61 Dazu P. Kondylis, Konservativismus, 1986, S. 207 ff. 
gängigen Meinung des 18. Jahrhunderts, wenn er das Volk ideell als eine künstliche, durch eine allgemeine Übereinkunft gegründete Korporation bezeichnet ${ }^{62}$. Doch spricht er dann sofort von der jeweils besonderen Natur des agreement eines Volkes und führt diese auf die Form zurück, in die das Geschick die jeweilige besondere Gesellschaft "gegossen" hat (cast). Dieses je besondere politische Sosein nennt Burke Verfassung (constitution). Sie ist als ein Geflecht von Über- und Unterordnungen, Kontrollen und Balancen, Antrieben und Gegenkräften, Einstellungen und Gewohnheiten nach seiner Überzeugung weder auf der Grundlage einer Theorie verfertigt noch so jemals herzustellen, sondern ein Produkt der Geschichte. Damit steht unser Autor in der Tradition der schottischen Moralphilosophen mit ihrer Kritik an dem vorrevolutionären Versuch, gewachsene Lebensverhältnisse in den formalen Rechtsbegriffen eines Vernunftrechts zu rekonstruieren $^{63}$. Ihre Rechtfertigung findet die Verfassung nach Burke allein in ihrer historischen Bewährung. Sie verleiht den einzig wirklichen Rechtstitel, nämlich den der Ersitzung (prescription): nur der Ablauf der Zeit macht behauptetes Recht stark. Und allein die Geschichte vermag so Rechtsgemeinschaften hervorzubringen. Schon vor seinen berühmten und einflußreichen "Betrachtungen über die Revolution in Frankreich" von 1790 hat Burke die Nation in diesem Sinne als Kontinuitätsbegriff bezeichnet ${ }^{64}$. Der damit angesprochene Zusammenhang meine das politische Handeln vieler Generationen unter

62 E. Burke, An Appeal from the New to the Old Whigs, in: Works IV, London, 1899, S. 57 (169). Hierzu u. zum folg. Hofmann, Repräsentation (N 28), S. 454 ff.

63 Man denke an D. Humes Kritik der Lehre vom Gesellschaftsvertrag: Of the Original Contract (1748), dt. in: ders., Politische und ökonomische Essays, hg. v. U. Bermbach, Bd. 2, 1988, S. 301 ff.; und an A. Fergusons Diktum: "Keine Verfassung wird durch eine Verabredung gebildet, keine Regierung entspricht der Kopie eines Plans «: An Essay on the History of Civil Society (1767), dt. u. d.T. Versuch über die Geschichte der Bürgerlichen Gesellschaft, 1986, S. 259.

64 Burke, Speech against Pitt's proposal, in: Historical Documents X, London 1957 , S. $225(226)$. 
einer Fülle der verschiedensten Einflußfaktoren. Eine derartige Rechtsgemeinschaft als Grund allen aktuellen Rechts und seiner Verbindlichkeit besteht in der Weitergabe und Fortentwicklung gelebter Ordnungen. Sie erscheint als ein realer transpersonaler Handlungszusammenhang mit eigener Subjektivität, die in der Bezeichnung als Nation zum Ausdruck kommt. Ihr, der Nation, können Attribute beigelegt und Tätigkeiten zugeschrieben werden. Gleichwohl ist dieses transpersonale Subjekt aber nicht ich-haft selbstbewußt gedacht, keine ins Riesenhafte gesteigerte Person, kein Über-Ich, sondern ganz unpersönlich, zudem fließend und dynamisch - ein "Es «.

Dieser transpersonale Entwicklungsgedanke fand - namentlich in der Romantik und über sie - breite Resonanz ${ }^{65}$. Savigny wandte ihn nationalhistorisch gegen die Ausstrahlung der revolutionären Napoleonischen Gesetzgebungswerke, indem er das Recht zu einem nicht beliebig disponiblen Aspekt des geschichtlich sich formenden Volkslebens erklärte ${ }^{66}$. Das Recht wachse und vergehe mit dem Volke. Es entwickle sich im "organischen Zusammenhang " mit dessen Wesen und Charakter und habe daher im Grunde so wenig wie Sprache, Sitte und Verfassung ein "abgesondertes Daseyn". Alles Recht entstehe mithin als Gewohnheitsrecht, d.h. "erst durch Sitte und Volksglaube, dann durch Jurisprudenz . . , überall also durch innere, stillwirkende Kräfte, nicht durch die Willkür eines Gesetzgebers ${ }^{67}$. Folglich ist das Recht für ihn in erster Linie - und darin liegt die eigentliche politische Spitze - Angelegenheit der

65 Dazu W. Lepenies, Historisierung der Natur und Entmoralisierung der Wissenschaften seit dem achtzehnten Jahrhundert, in: Natur und Geschichte, hg. v. H. Markl, 1983, S. 263 (275 ff.).

66 F.C. v. Savigny, Vom Beruf unserer Zeit für Gesetzgebung und Rechtswissenschaft (1814), zit. nach: Thibaut und Savigny, hg. v. J. Stern, 1959, S. 69 ff.; die folg. Zit. ebd. S. $76 \mathrm{ff}$.

67 Ebd. S. 79. Siehe dazu Puchtas zweiteiliges Werk über das Gewohnheitsrecht von $1828 / 37$ und hierüber G. Bohnert, Über die Rechtslehre Georg Friedrich Puchtas, 1975 , S. $66 \mathrm{ff}$. 
Rechtsgelehrten und nicht Sache monarchischer Bürokratien oder demokratischer Parlamente. Savignys Historische Rechtsschule setzt so gegen die Kleinstaaterei wie gegen die politischen Änderungsbestrebungen auf die Einheit der bürgerlichen Kulturnation. Zugleich wurde damit der Grund für Selbstbewußtsein und Selbstsicherheit einer aus langer sachlicher Überlieferung lebenden Zivilrechtsdogmatik gelegt.

Freilich hat diese historische Betrachtungsweise auch ein aus tiefer Skepsis geborenes eher negatives Seitenstück, das zugleich ein Gegenstück zu Montaigne, Bodin und Hobbes ist. Es findet sich in Blaise Pascals Pensées (Nr. 294) und lautet: "Die Gewohnheit allein macht das ganze Recht; daß es überliefert ist, ist sein einziger Grund; sie ist das mystische Fundament seiner Autorität. " Pascal wollte damit indes vornehmlich zum Ausdruck bringen, daß allem Recht der wahre Grund in der Gerechtigkeit fehle und daß die Frage nach der Gerechtigkeit folglich zerstörerisch wirke: „Wer es (das Recht) auf seinen wahren Grund zurückführen will, hebt es auf."

Hegel macht aus den Volksgeistern der verschiedenen Nationen den einen Weltgeist, dessen Totalität oder Ganzheitswahrheit trotz der behaupteten einen zu sich selbst kommenden Subjektivität aller partikulären subjektiven und objektiven geistigen Prozesse gleichfalls nicht mehr ich-haft gedacht werden $k a_{n}{ }^{68}$. Hegels Rechtsphilosophie wird auf diese Weise zu einem Teil seiner christlich-pantheistischen Geschichtsphilosophie. Folglich leugnet auch Hegel, daß Verfassungen gemacht werden könnten: die Verfassung sei ein Organismus ${ }^{69}$, wiewohl "in der Zeit hervorgegangen ", dürfe sie (normativ) "nicht als ein Gemachtes angesehen werde(n); denn sie (sei) vielmehr das schlechthin an und für sich Seiende, ... das

68 Zur objektiv-idealistischen Strukturverwandtschaft von Savigny und Hegel J. Rükkert, Idealismus, Jurisprudenz und Politik bei Friedrich Carl von Savigny, 1984, bes. S. $301 \mathrm{ff}$.

69 Rechtsphilosophie (Ed. Suhrkamp Bd. 7) $\$ 269$ (S. 414). 
Göttliche und Beharrende ${ }^{70}$. Auch das Recht erscheint, weil Ausdruck der Freiheitsidee, als »etwas Heiliges « (Rph. § 30), gewinne Verbindlichkeit freilich erst im Gesetz, insofern dies mit dem in Gedanken gegebenen Ansichsein des Rechts identisch sei (Rph. $\S \S 211,212)$. Und die dementsprechend gesetzte Rechtsordnung gehe dann in der objektiven Sittlichkeit auf, wenn zudem auch die subjektive Gesinnung der Rechtsgenossen diejenige des an sich seienden Rechts sei (Rph. § 141).

Der Abstand von allen personalen Begründungstheorien über Gebot und Vertrag ist groß. Er wird durch den Gedanken der Verfügbarkeit und den der Unverfügbarkeit des Rechts markiert. Charakteristisch für die unpersönlichen Begründungslehren sind zudem die große Bedeutung von Betrachtung und Erkenntnis, der Gestus des Bewahrens und die Relativierung der Individualität.

Es sind die "sittlichen Mächte«, nämlich Familie, bürgerliche Gesellschaft und Staat, die nach Hegel als das Objektive und Notwendige das Leben der Individuen regieren, auch wenn jene sittlichen Mächte Vorstellung, Gestalt und Wirklichkeit nur in den Individuen haben, die indes doch bloß "Accidenzen « sind: Zufälliges (Rph. § 145 mit Zus.).

Besonders aber fällt in diesem Kontext auf, daß dem Recht (was mit der Frage seiner Verfügbarkeit zusammenhängt), die Eigenständigkeit abgesprochen und es als spezielle Erscheinung von etwas anderem genommen wird - ähnlich wie zuerst Montesquieu das Recht als Ausdruck der Lebensverhältnisse begriffen hatte. Recht ist danach "recht", wie Kant schrieb" oder "Rechtens", wie Hegel sagte ${ }^{72}$, also richtig oder wesent-

70 Ebd. $\$ 273$ a.E. (S. 439); vgl. dazu ebd. § 274 (S. 440) Zusatz: »... eine Verfassung ist kein bloß Gemachtes: sie ist die Arbeit von Jahrhunderten, die Idee und das Bewußtsein des Vernünftigen, inwieweit es in einem Volk entwickelt ist. Keine Verfassung wird daher bloß von Subjekten geschaffen."

71 Metaphysik der Sitten (N 4), S. 34.

72 Rechtsphilosophie (N 69), § 212 (S. 365). 
lich und damit verbindlich, wenn und soweit darin etwas GröBeres, Höheres, Umfassenderes wie das Leben, die Natur, der Geist eines Volkes oder der Weltgeist sich ausdrückt. "Das Recht existiert nur als Zweig eines Ganzen «, heißt es bei Hegel, "als sich anrankende Pflanze eines an und für sich festen Baums ", nämlich der Idee des sittlich Guten (Rph. § 141 Zus.). Jenes Umfassende und Ganze kann aber - und damit sind die ontologischen wie die rationalistischen Naturrechtslehren angesprochen - auch Weltseele, Welt der Ideen und Werte, Vernunft, Natur oder Schöpfung heißen. Heute sind es die sogenannten Kommunitarier, die in den USA gegen das individualistische liberale Gesellschaftsmodell in einer neoaristotelischen Weise ganzheitlich argumentieren ${ }^{73}$, damit zu einer natürlichen sozialen Zugehörigkeitspflicht des einzelnen (natural obligation to belong) und so zu einer natürlichen politischen Gehorsamspflicht gelangen ${ }^{74}$.

Die prinzipielle Differenz zwischen den personalen und den unpersönlichen Theorien der Geltungsbegründung findet ihre grammatikalische Entsprechung in dem Umstand, daß seit W.v. Humboldts Untersuchungen die Formen der ersten und zweiten Person von Sprechenden und Angesprochenen einerseits und die sog. dritte "Person" des Besprochenen sprachwissenschaftlich auf ganz verschiedenen Ebenen gesehen werden $^{75}$. Würde das Ganze nicht formal durch die dreiteilige grammatikalische Kategorie der Personalpronomina strukturiert, könnte man also auch von einem Theorien-Dualismus

73 Dazu statt aller A. Honneth (Hg.), Kommunitarismus, 1993.

74 Ch. Taylor zit. nach W. Kersting, Liberalismus, Kommunitarismus, Republikanismus, in: Zur Anwendung der Diskursethik in Politik, Recht und Wissenschaft, hg. v. K.-O. Apel u. M. Kettner, 1992, S. 127 (143). Siehe dazu die Beiträge zum "Symposium on Duties beyond Borders «, in: Ethics, Vol. 98 (1987/88), S. $647 \mathrm{ff}$.

75 Dazu W. v. Humboldt, Über den Dualis, in: Werke, hg. v. A. Flitner u. K. Giel, Bd. III, 6. Aufl. 1988, S. 113 ff.; E. Benveniste, Problèmes de linguistique générale, Paris 1972, dt. u. d. T. Probleme der allgemeinen Sprachwissenschaft, 1974, S. $280 \mathrm{ff}$; $H$. Thun, Personalpronomina für Sachen, 1986, S. $81 \mathrm{ff.}, 119 \mathrm{ff}$. 
sprechen: auf der einen Seite die personalen, im Ich und ÜberIch oder im Du und Wir zentrierten Begründungslehren und auf der anderen Seite die vielfältigen es-haften Theorien vom Grund und der Verbindlichkeit des Rechts. Und man dürfte mit um so mehr Berechtigung von einem solchen Dualismus sprechen, als die im Gedanken des Gebots zentrierten Begründungslehren ihre eigenständige Bedeutung verloren zu haben scheinen. Denn seit Nietzsche versuchte, das moderne Subjekt in Natur zurückzuübersetzen ${ }^{76}$, ist das souveräne Ich - mag das Subjekt in der sog. Postmoderne nun vollends untergegangen sein, wie man gesagt hat ${ }^{77}$, oder nicht - jedenfalls entthront, so wie die absoluten Monarchen längst vor ihm.

Nicht anders als die Begründungslehren der Du-Wir-Grammatik haben auch die Argumentationen aus einem un- oder überpersönlichen Kontext heraus ihre strukturspezifischen Probleme. Sie sind hauptsächlich von zweierlei Art. Zum einen fragt sich, ob die Verbindlichkeit des Sollens hier nicht zum Müssen mutiert. Einsicht in die Gegebenheiten, so hat es Durkheim für seine ganzheitliche Auffassung vom sozialen $\mathrm{Ge}$ schehen ausgedrückt, führe zur Unterordnung und wecke »Gefühle der Ergebenheit und des Respekts « ${ }^{78}$. Nicht viel anders schrumpft die Moralität des Rechts in Hegels Rechtsphilosophie zur verinnerlichten Legalität. Die Kategorie des Sollens verliert ihre Eigenständigkeit. "Was sein soll, ist in der Tat auch, und was nur sein soll, ohne zu sein, hat keine Wahrheit", sagt Hegel schon in seiner »Phänomenologie des Geistes « ${ }^{79}$.

76 H. Hofmann, Nietzsche, in: Klassiker des politischen Denkens, hg. v. H. Maier u. a. Bd. 2, 5. Aufl. 1987, S. 276 (283 ff.).

77 Dazu G. Dux, Der Täter hinter dem Tun, 1988, S. 28 ff. (in dieser Reihe Heft 6), sowie die einschlägigen Beiträge in: Postmoderne - globale Differenz, hg. v. R. Weimann u. H.U. Gumbrecht, 1991.

78 E. Durkheim, Die Regeln der soziologischen Methode, hg. v. R. König, 2. Aufl. 1965, S. 107 ff., $201 \mathrm{ff} ., 203$.

79 Ed. Suhrkamp Bd. 3, S. 192; siehe auch ders., Enzyklopädie der philosophischen Wissenschaften, $\S \S 6$ u. 234; dazu $O$. Marquard, Hegel und das Sollen, in: ders., Schwierigkeiten mit der Geschichtsphilosophie, 1972, S. $37 \mathrm{ff}$. 
Das andere Problem ist die Spaltung des Rechtsbegriffs. Denn letztlich wird hier den vorfindlichen, historisch kontingenten Gesetzen der Gedanke eines überzeitlich richtigen oder eines geschichtlich eigentlich wirklichen Rechts gegenübergestellt. Das führt einmal zur schwierigen Frage der Unterscheidung zwischen guten und schlechten, wesentlichen und unwesentlichen Traditionen. Zum anderen stellt sich das Problem der Hierarchisierung. Denn wenn es nicht gelingt, den Geltungsvorrang jener höheren Normen vor den menschlichen Satzungen zu behaupten, wie die stoisch-christliche Tradition dies tat ${ }^{80}$, dann fallen die Begriffe auseinander, und es dominieren die formalisierten und faktisch durchgesetzten Regeln der jeweiligen politischen Ordnung ${ }^{81}$. Rechtswissenschaftlich entspricht dem ein positivistischer Rechtsbegriff, der den Gedanken überzeitlich richtigen Rechts in den Bereich beliebiger subjektiver Moralvorstellungen abdrängt. Philosophisch hat Kant, dessen Begründung der Verbindlichkeit des positiven ("empirischen") Rechts sich zwischen Fremd- und Selbstbestimmung im Schema des Gebots bewegt, mit seinen synthetischen Rechtssätzen a priori gegen das bloß gesetzte Recht idealistische Lehren einer "Metaphysik der Sitten" entwickelt. Die Geltung jener Rechtssätze ist zwar nicht wie die des positiven Rechts wirklich, sondern nur möglich, erscheint gleichwohl aber vernunftnotwendig ${ }^{82}$. Ihr Idealismus bleibt indes, an die Personhaftigkeit des Menschen gebunden, subjektiv, entspringt nicht einem transpersonalen objektiven An-sich.

80 Siehe z.B. Thomas von Aquin, Summa theologica I/II 94,5; I/II 95,2; II/II 57,2.

81 Dazu u. zum folg. $R$. Dreier, Rechtsbegriff und Rechtsidee, 1986 (in dieser Reihe Heft 5).

82 J.v. Kempski, Recht und Politik, 1965, S. 13; dazu Hofmann, Autonomieansprüche (N 7), S. 167. 


\section{VII.}

Zum Schluß sei noch auf eine Wiederholung des Aufrufs Savignys von 1814 zur Besinnung auf die Wurzeln des Rechts und die Aufgabe der Rechtswissenschaft aus den Jahren 1943/44 hingewiesen. Damals hat der eingangs erwähnte umstrittene Staatsrechtler Carl Schmitt vor europäischen Rechtsfakultäten einen Vortrag über "Die Lage der europäischen Rechtswissenschaft" gehalten. Schmitt selbst bezeichnete ihn die Namen Savignys und des Mutterrechtlers Bachofen »beschwörend " - als einen "Aufruf zur Rechtswissenschaft als der letzten Hüterin der absichtslosen Entstehung und Entwicklung des Rechts«.

Darin (- oder genauer: in der Druckfassung von $1950^{83}$-) finden sich einige bemerkenswerte Sätze. Im Europa jener Jahre sei "die Rechtswissenschaft zum letzten Asyl des Rechtsbewußtseins « geworden. Dieses Rechtsbewußtsein manifestiere sich - und nun werden fundamentale Rechtsprinzipien und -einrichtungen beschworen - in der Wahrung der "Grundlage(n) eines rationalen Mensch-Seins, das der Prinzipien des Rechts nicht entbehren kann. Zu diesen Prinzipien gehört eine im Kampf nicht entfallende, auf gegenseitiger Achtung beruhende Anerkennung der Person; Sinn für Logik und Folgerichtigkeit der Begriffe und Institutionen; Sinn für Reziprozität und für das Minimum eines geordneten Verfahrens, einen due process of law, ohne den es kein Recht gibt". Diese im Vergleich zu den schneidigen Ausführungen desselben Verfassers aus früheren Jahren vielleicht überraschenden, angesichts der bevorstehenden Niederlage Deutschlands aber nur allzu verständlichen Darlegungen führen am Schluß zu den folgenden

83 Zit. nach: Verfassungsrechtliche Aufsätze, 2. Aufl. 1973, S. 386 ff.; die nachfolg. Zit. S. 422 f. u. 426 . Nach dem seit 1945 besonders stark ausgeprägten Hang Schmitts zur Selbststilisierung ist hier mit stillschweigenden Abweichungen von der Originalfassung zu rechnen. 
Sätzen: "Auch im Terror der Vernichtungsmittel, die eine moderne Naturwissenschaft jedem Machthaber an die Hand gibt, wird eine restlos auf sich selbst zurückgeworfene Rechtswissenschaft die geheimnisvolle Krypta zu finden wissen, in der die Keime ihres Geistes vor jedem Verfolger geschützt sind." Und: "Die europäische Rechtswissenschaft braucht nicht mit den Mythen vom Gesetz und Gesetzgeber eines gemeinsamen Todes zu sterben. Besinnen wir uns wieder auf unsere Leidensgeschichte, denn unsere Kraft wurzelt in unserem Leidvertrauen."

Diese quasi rechtspriesterlich beschwörende Gebärde des Hüters weist über die Situation hinaus. Sie ist charakteristisch für ein unpersönliches, es-haftes Rechtsdenken - so wie das Anerkennen einer Autorität, das Hören, Nachdenken und Erklären ihrer Äußerungen, aber auch die egalitäre Kommunikation in der Treue zu den konsentierten Prinzipien typische Grundhaltungen sind. Schmitts Erwähnung Bachofens und die - freilich ein bißchen aufgesetzte - Verwendung bestimmter Worte und Bilder wie des passiven Hervorbringens, der geheimnisvollen Höhle, der Keime des Geistes und der Kraft aus dem Leid bedeuten zugleich die Beschwörung matriarchalischer Urbilder ${ }^{84}$. Sie lassen sich diesem Typus des Rechtsdenkens offenbar leicht amalgamieren. Viel eher jedenfalls als dem autoritären Vatergebot oder dem Vertragsgedanken, der leicht

84 Dazu U. Wesel, Der Mythos vom Matriarchat, 1980; H.-J. Heinrichs (Hg.), Das Mutterrecht von Johann Jakob Bachofen in der Diskussion, 1987. - Das Recht schlechthin als Mutter hat schon R. Hooker (Of the Laws of Ecclesiastical Polity I 16.8) gefeiert: Of law there can be no lesse acknowledged, then that her seate is the bosome of God, her voyce the harmony of the world, all thinges in heaven and earth doe her hommage, the very least als feeling her care, and the greatest as not exempted from her power, but Angels and men and creatures of what condition so ever, though ech in a different sort and maner, yet all with uniforme consent, admiring her as the mother of their peace and joy. (Zit. nach The Folger Library Edition I, 1977, S. 142). Den Hinweis auf diese Stelle verdankt Verf. Professor Onora O'Neill, Oxford. 
etwas Jungmännerbündisches hat ${ }^{85}$. So ist es auch kein Zufall, daß am Anfang des europäischen Naturrechtsdenkens eine Frau es ist, die im Zusammenstoß von traditioneller familiärer Moral und neuem Polis-Recht Kreons patriarchalischen Geboten der Staatsraison (vó $\mu \circ 1)$ die ungeschriebenen und untrügli-

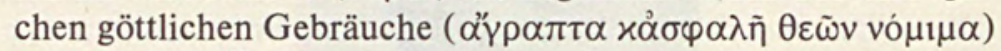
entgegensetzt ${ }^{86}$, die nicht von heute oder gestern sind und ohne Anfang immer leben, wie Antigone sagt ${ }^{87}$. Aber das wäre ein neues Thema.

85 Siehe dazu H. Marti, Urbild und Verfassung, Bern u. Stuttgart o.J. (1958), bes. S. 99 ff. - Hier ist auch auf die große Bedeutung der Entwicklungspsychologie von Piaget und Kohlberg für das Modell der Diskursethik hinzuweisen. Indem diese den Kern moralischen Verhaltens mit dem identifiziert, was als Erwerb und in die Lebensführung aufgenommener Gebrauch prüfender Verfahren die entscheidende moralische Reifungsstufe des Heranwachsenden ausmacht, rückt sie die Moral "nahe zum Wahrhaftigkeits- und Ehrbegriff des Jugendalters ... und (besitzt) darin selbst etwas erweckend Jugendhaftes ( $G$. Irrlitz, Moral und Methode, 1993, S. 17 - in dieser Reihe Heft 16).

86 Aristoteles, Rhetorik I 13; G. Steiner, Antigones, Oxford/New York 1984, dt. u. d.T. Die Antigonen, 1990, S. 34 ff.

87 Sophokles, Antigone $450 \mathrm{ff}$. 


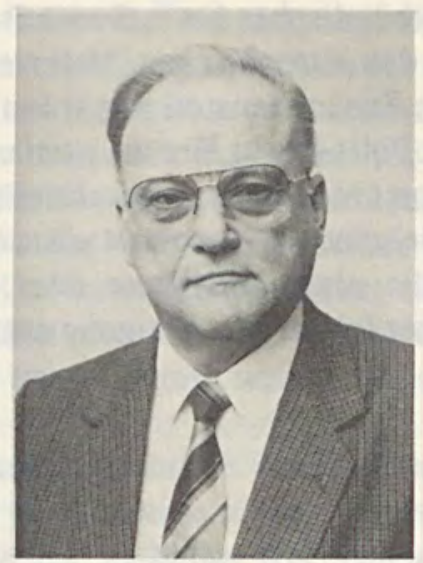

\section{Hasso Hofmann}

\section{Geboren 1934 in Würzburg}

1954-1959 Studium der Rechtswissenschaft in Heidelberg, München und Erlangen

1964 Promotion in Erlangen

$1970 \quad$ Habilitation in Erlangen

1970-1976 Universitätsdozent und a.o. Professor in Erlangen

1976-1992 Professor für Rechtsphilosophie, Staats- und Verwaltungsrecht an der Universitåt Würzburg

1988 Ruf auf einen Lehrstuhl für Öffentliches Recht an der Universität Freiburg/Br. (abgelehnt)

1989/90 Wissenschaftliches Mitglied (Fellow) am Wissenschaftskolleg zu Berlin

1991/92 Abordnung an die Humboldt-Universität zu Berlin

Seit 1992 Professor für Öffentliches Recht, Rechts- und Staatsphilosophie an der Humboldt-Universität zu Berlin

Ende 1992 Wahl zum Vizepräsidenten der Humboldt-Universität

Mitglied der Bayerischen und der Berlin-Brandenburgischen Akademie der Wissenschaften.

Selbständige Veröffentlichungen:

Legitimität gegen Legalität - Der Weg der politischen Philosophie Carl Schmitts, 1964, 2. Aufl. 1993; Der Herrschaftsvertrag (zus. mit A. Voigt u. P. Badura), 1965; Repräsentation - Studien zur Wort- und Begriffsgeschichte von der Antike bis ins 19. Jahrhundert, 1974, 2. Aufl. 1990; Legitimität und Rechtsgeltung - Verfassungstheore- 
tische Bemerkungen zu einem Problem der Rechtsphilosophie und der Allgemeinen Staatslehre 1977; Rechtsprobleme der atomaren Entsorgung, 1981; Grundpflichten als verfassungsrechtliche Dimension (zus. mit V. Götz), 1983; Recht - Politik - Verfassung. Studien zur Geschichte der politischen Philosophie, 1986; Privatwirtschaft und Staatskontrolle bei der Energieversorgung durch Atomkraft, 1989; Die versprochene Menschenwürde, 1993. 


\section{Würzburger Vorträge zur Rechtsphilosophie, Rechtstheorie und Rechtssoziologie}

Heft 1: Arthur Kaufmann: Theorie der Gerechtigkeit, Problemgeschichtliche Betrachtungen, 1984, 51 S., 19,80 DM

Heft 2:-

Heft 3: Niklas Luhmann: Die soziologische Beobachtung des Rechts, 1986,48 S., 16,80 DM

Heft 4: Ernst-Wolfgang Böckenförde: Die verfassunggebende Gewalt des Volkes - Ein Grenzbegriff des Verfassungsrechts, 1986, 34 S., 16,80 DM

Heft 5: Ralf Dreier: Rechtsbegriff und Rechtsidee, Kants Rechtsbegriff und seine Bedeutung für die gegenwärtige Diskussion, 1986, 37 S., 18,80 DM

Heft 6: Günter Dux: Der Täter hinter dem Tun, Zur soziologischen Kritik der Schuld, 1988, 58 S., 24,- DM

Heft 7: Franz Bydlinski: Recht, Methode und Jurisprudenz, 1987, 46 S., 19,80 DM

Heft 8: Martin Kriele: Freiheit und,Befreiung“, Gibt es eine Rangordnung der Menschenrechte?, 1988. 52 S., 26,-DM

Heft 9: Manfred Rehbinder: Fortschritte und Entwicklungstendenzen einer Soziologie der Justiz, 1989, 63 S., 26,- DM

Heft 10: Klaus Lüderssen: Die Krise des öffentlichen Strafanspruchs, 1989, 62 S., 26,- DM

Heft 11: Norbert Hoerster: Verteidigung des Rechtspositivismus, 1989, 31 S., 26,- DM

Heft 12: Guiseppe Duso: Der Begriff der Repräsentation bei Hegel und das moderne Problem der politischen Einheit, 1990, 55 S., 24,-DM

Heft 13: Otfried Höffe: Gerechtigkeit als Tausch? Zum politischen Projekt der Moderne, 1991, 37 S., 18,- DM

Heft 14: Klaus F. Röhl: Die Gerechtigkeitstheorie des Aristoteles aus der Sicht sozialpsychologischer Gerechtigkeitsforschung, 1992, 59 S., 26,- DM 
1

ISBN 3-7890-3194-1 